
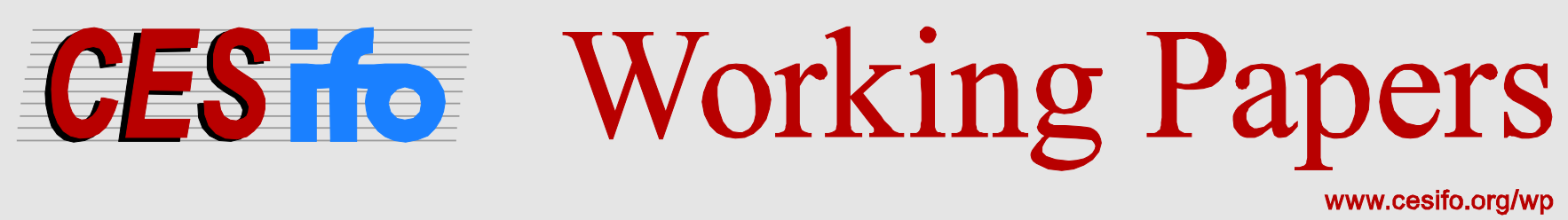

\title{
A Simple Model of Globalization, Schooling and Skill Acquisition
}

\author{
Carl Davidson \\ Nicholas Sly
}

\author{
CESIFO WORKING PAPER NO. 4394 \\ CATEgORY 6: FiscAl POLICY, MACROECONOMICS AND GROWTH \\ SEPTEMBER 2013
}

An electronic version of the paper may be downloaded

- from the SSRN website:

- from the RePEc website:

- from the CESifo website:

wWW.SSRN.com

Www.RePEc.org

www.CESifo-group.org/wp

\section{CESifo}




\title{
A Simple Model of Globalization, Schooling and Skill Acquisition
}

\begin{abstract}
We develop a model of schooling and skill acquisition, highlighting informational asymmetries that distort the incentives to educate. A key feature of our model is that education acts simultaneously as a signaling device and as a method for workers to enhance their productivity. We show that when firms can only imperfectly screen workers, the result is an economy in which too many workers purchase schooling and too few workers devote sufficient effort to their coursework to qualify for the high skill labor pool. We then examine how greater openness to international markets alters the skill mix of the domestic workforce and show that greater openness usually eases one labor market distortion while making the other distortion worse. Globalization impacts educational behavior and labor market outcomes differently as the extent of firms engaged in international markets varies, and affects wage inequality both within and across educational groups.
\end{abstract}

\author{
Carl Davidson \\ Department of Economics \\ Michigan State University \\ 25C Marshall Adams Hall \\ USA - East Lansing, MI 48824 \\ davidso4@msu.edu
}

\author{
Nicholas Sly \\ Department of Economics \\ University of Oregon \\ USA - 97403-1285 Eugene Oregon \\ sly@uoregon.edu
}

June 2013

We have benefited from seminars at Princeton University, Purdue University, Science Po, as well as comments received during discussions at the West Coast Trade Workshop. In particular we are indebted to Matilda Bombardini, Gabriel Felbermayr, Lionel Fontagne, Gene Grossman, Arijit Mukherjee, Stephen Redding, Jonathan Vogel, and Glen Waddell. Any remaining errors are our responsibility. 


\section{Introduction}

It is often argued that the key to individual success in a globalized economy lies in higher education. From a national perspective, a highly educated workforce is seen as an essential component needed to maintain international competitiveness and foster economic growth. Yet, the educational process is complex, requiring a variety of individual choices, and the manner in which globalization affects those choices is not well understood. In this paper we develop a simple model of schooling and skill acquisition, highlighting informational asymmetries that distort the incentives to educate. We then examine how greater openness to international markets alters the skill mix of the domestic workforce, given that worker schooling and skill acquisition decisions are not perfectly observed by firms.

The notion that educational choices might be distorted is not new. Forty years ago Ivar Berg (1970) and Richard Freeman $(1975,1976)$ argued that `too many’ Americans seek a college education. More recently, Charles Murray, in Real Education: Four Simple Truths for Bringing America's Schools Back to Reality (2009), pushed this same idea, arguing that the marginal student in college today would be much better off going to a trade school. ${ }^{1}$ For anyone who has taught at a large state university and dealt with students who rarely come to class and seem to devote almost no effort to the educational process, this sentiment probably rings true. On the other hand, we often hear that firms are complaining that they cannot find enough high-skilled workers to fill available positions. For example, in a 2012 survey the ManpowerGroup found that $34 \%$ of employers across the globe report that they are having difficulty filling positions due to a lack of available talent among the labor force. In a 2012 study by the McKinsey Global Institute it was concluded that "[i]n advanced economies, demand for high-skilled labor is now growing faster than supply...,” so the shortage of high skill workers may actually be growing.

These anecdotal pieces of evidence are seemingly at odds with one another. How can it be that there are simultaneously 'too many' workers earning advanced degrees in school, yet there are 'too few'

\footnotetext{
${ }^{1}$ In an interview with the New York Times, Murray argued "there are very few unemployed first-rate electricians. I can get a good doctor in a minute and a half. Getting a really good electrician - that's hard.” -- see Solomon (2008) for additional details. Carneiro, Heckman and Vytlacil (2011) provide evidence consistent with Murray's claims that the marginal return to college is often well below the average return. They argue that policies that expand college enrollment induce "students who should not attend college to attend it. Too many people go to college."
} 
high-skill workers available for hire? We argue that such a market condition can arise if the efforts that workers put forth during school, and hence the benefits of their high skills to productivity, are not perfectly observed when firms screen applicants. If high skill workers cannot perfectly distinguish themselves from low skill workers that obtained schooling solely as a signaling device, then the problem of adverse selection arises in the labor market. Firms compensate for the lack of information about skills by offering wages that reflect the average productivity of the educated workers, rather than their marginal productivity. As a result, too many low aptitude workers choose schooling because the expected returns to education are higher than their individual productivity. Likewise, too few high aptitude workers put forth effort in school to enhance their productivity because the returns to education do not fully compensate them for being high skilled if there is imperfect screening. A key feature of our analysis is to model skill acquisition as simultaneously a signaling device and a mode for workers to enhance their productivity, which allows us to rationalize the opposing views of the labor force as having both too many workers obtaining advanced degrees, and too few high skill workers. ${ }^{2,3}$

Globalization has long been recognized as a mechanism that shifts the relative demand for skilled workers, and thus the expected returns from education and skill acquisition. Hickman and Olney (2011) provide direct evidence that the offshoring of local production, and international migration into local labor markets, both induce U.S. workers to enroll in post-secondary education institutions. Atkin (2012) provides empirical evidence that young Mexican workers respond to increased export opportunities for low-skill occupations by reducing their enrollment in school, whereas greater export opportunities for

\footnotetext{
${ }^{2}$ Fang (2006) uses a structural model to quantify the relative importance of signaling motives and productivity enhancement in explaining the college wage premium in the US and finds that both motives contribute substantially to educational incentives. Similarly, Lange (2007) estimates the speed of employer learning about worker attributes and finds both signaling and productivity enhancement are persistent motives that influence educational behavior.

${ }^{3}$ Our approach here is different from the empirical literature on over-education, as indicated by the qualifications of individual workers that are in excess of their specific job requirements. As an example, as of 2010, the Bureau of Labor Statistics reported that over 17 million Americans with college degrees are employed in positions that require a lower level of skills than those associated with a college degree. More details can be found in Matgouranis (2010) who reports that: $29.8 \%$ of flight attendants, $24.5 \%$ of retail salespersons, $21.6 \%$ of customer service representatives, $15.2 \%$ of taxi drivers, and $13.9 \%$ of mail carriers hold college degrees. For a recent review of the literature on mismatches between worker skills and job tasks see Leuven and Oosterbeek (2011). Our analysis of educational behavior when there are informational asymmetries across the entire market is distinct from, but complementary to, the studies of mismatch and coordination problems for individual workers.
} 
high-skill occupations increase the acquisition of schooling among Mexican workers. There is similar evidence in Falvey, Greenaway, and Silva (2010) of skill-upgrading among Portuguese workers as international competition intensifies. It is clear that the expansion of the global economy influences the schooling and skill acquisition of native workers. However, it is unclear if changes in the educational behavior of workers following episodes of globalization mitigate, or exacerbate, the distortions present when firms screen worker skills imperfectly. Our goal here is to examine the impact of increased trading opportunities on (i) the decisions of workers to go to school, and (ii) the decisions of workers to obtain high levels of skill, when workers have more information about their skills than hiring firms.

To analyze the impact of globalization on the mix of worker skills, we build a two-sector model with perfectly competitive markets. Workers differ in aptitude and can choose to go to school to become a low-skill worker, and subsequently choose whether to put forth effort to become a more productive high-skill worker. Both schooling and effort are costly, and the costs are each declining in the innate aptitude of workers. The schooling decisions of workers are observed through the earning of a degree, however the efforts of workers toward improving their productivity are not observable. Firms can screen for high skill workers, but the screening technology is imperfect.

In one sector of the economy, output is produced by identical firms using unskilled labor, while the other good requires skilled labor, and can be produced using two different technologies: the basic technology utilizes low-skilled labor but the modern technology requires high-skilled workers. Firms that adopt the basic technology hire less productive workers but also pay lower wages so that firms of both types can co-exist in equilibrium. We show that when there are heterogeneous firms, who differ in the skill intensity of their production techniques, the autarky and open economy equilibria are unique - even when worker skills are not perfectly observed.

The ability to flexibly choose the skill intensity of their production techniques gives firms an additional margin, besides adjusting wages, on which they can respond to information asymmetries, eroding the potential for multiple equilibria. In previous analyses of imperfect labor markets, where workers use education to both signal skills and enhance productivity, multiplicity of equilibria has 
generally made it difficult to characterize equilibrium outcomes, at least without imposing structural assumptions. ${ }^{4}$ Instead we simply rely on the empirically relevant assumption that firms differ in their choice of production techniques across skill, even within narrowly defined industries. ${ }^{5}$ Importantly, the propensity of firms to adjust their production techniques in order to absorb changing supplies of educated workers is consistent with the evidence in Ciccone and Peri (2011). We note that, although the market allocation under asymmetric information is unique, the educational behavior of workers is still distorted. We analyze the efficacy of both globalization and educational policies in alleviating these distortions.

Changes in trading opportunities impact educational behavior by shifting the relative demand for skills across industries and firms. There is strong evidence that firms face a fixed cost to gain access to world markets (e.g., Roberts and Tybout 1997), so that firms with different productivities face varying incentives to export. As a result, the impact of greater access to foreign markets on skill-acquisition can vary according to the share of firms engaged in export activity. In an equilibrium in which only a share of the most productive firms export, globalization induces more workers to obtain high skills, partially alleviating the inefficiency in skill acquisition behavior. However, when a relatively large share of firms export, greater market access benefits firms that hire both low and high skilled workers, so that the incentives to obtain high skills at the margin are smaller; in that case globalization exacerbates inefficient skill acquisition behavior. In terms of schooling, we find that greater export opportunities always exacerbate the over education distortion by inducing more workers to use schooling simply as a signal.

Changes in educational behavior reflect the manner in which wages adjust in equilibrium. Here we highlight that - because workers that use education as a signal are indistinguishable to firms (and

\footnotetext{
${ }^{4}$ The potential for multiple equilibria in the presence of asymmetric information has long been recognized. The classic treatment of this issue is from Wilson (1980). Rose (1993) numerically examines the potential for multiple equilibria in adverse selection settings like those studied by Wilson. Even abstracting from the possibility to signal the market, several well-known distributions of unobserved quality (i.e., worker ability) generate multiple equilibria, including the normal distribution that accords well with the 'Bell Curve' often used to describe student performance. A recent analysis where workers acquire schooling to both signal skills and enhance their own productivity is Blankenau and Camera (2006), who demonstrate that generally there are multiple stationary equilibrium.

${ }^{5}$ Doms, Dunne and Troske (1997) demonstrate that firms within U.S. manufacturing industries differ according to the skill intensity of their production techniques. It is also worth noting that there is substantial evidence that exporting firm differ in skill intensity (Bernard and Jensen 1999) and that changes in international competition impact the relative demand for skills within and across firms within industries (Pavcnik 2003 and Fernandes 2007).
} 
econometricians!) from those that use schooling for productivity enhancement - the impacts globalization on wage inequality manifest both within and across educational groups. Lemieux (2006a,b) demonstrates that much of the ubiquitous rise in wage inequality over the last four decades is concentrated within educational groups, in addition to change in the skill premium across educational groups. He also provides evidence that residual wage variation among post-secondary educated workers has risen, which he argues is best explained by an empirical model with heterogeneous returns to education. Incorporating both signaling and productivity motives for educational allows us to capture this relevant feature. ${ }^{6}$

The potential for information problems to distort labor market outcomes and educational decisions has long been recognized. Spence (1973) first described the role of costly education as a signal for skill when firms have less information about worker skills. The role of education as a signal is complementary to the traditional role of education for productivity enhancement studied by Becker (1964) and Mincer (1974). ${ }^{7}$ There are few analyses that nest both the signaling and productivity enhancing roles of education, which may be an important oversight given the evidence in Fang (2006) that both the signaling and productivity enhancing motives to educate are quantitatively important in explaining the college premium among the US workforce. Similarly, Lange (2007) estimates an upper bound of $15 \%-40 \%$ on the value of schooling that is due to signaling, supporting the idea that both motives are empirically relevant.

Many facets of the global economy are intimately connected to the distribution of worker skills in each country. Yet, the common approach it to treat the distribution of skills as a fixed endowment within countries, and as an innate characteristic of workers. There are a few notable exceptions. The classic

\footnotetext{
${ }^{6}$ As we do here, Blankenau and Camera show that imperfect information about worker skills can lead to adverse selection, with over education, under accumulation of skills, and wage dispersion among similarly skilled workers. However they assume that the demand for skills across agents are fixed, and find that there are multiple equilibria, complicating policy analysis. Also, their analysis is silent on the role of globalization in influencing labor market outcomes. Krugman (2000) exploits the potential for multiple equilibria generated by asymmetric information in labor markets with adverse selection to explain rapid changes in wage inequality observed across several countries in recent decades as an alternative to other mechanisms such as globalization or skill-biased technological change.

${ }^{7}$ Here we note that our view of the productivity enhancements that workers receive by exerting effort are general at the sector or aggregate level, rather than being firm-specific. Acemoglu and Pischke (1998) have analyzed the human capital accumulation decision when skills can be general or particular to a specific employer.
} 
treatment of endogenous human capital accumulation with international trade is in Findlay and Kierzkowski (1983), which examines the educational behavior of workers across countries that differ in their relative factor endowments. Subsequently, open economy analysis with endogenous human capital choices have shown that trade also interacts with features such as worker ages, national education policies, credit constraints or diversity of occupations in the choice to go to school; see Falvey et al. (2010), Bougheas et al. (2011, 2012), Ranjan (2001) and Blanchard and Willmann (2011). Perhaps the most closely related analysis of international trade with endogenous human capital acquisition is Vogel (2007). He investigates trade patterns with human capital accumulation with information problems that generate moral hazard issues. As with the previously mentioned analyses, education is purely productivity enhancing, allowing skilled managers to better detect the efforts of subordinate employees. He does not investigate adverse selection problems associated with imperfect observation of educational behavior. Our inclusion of education as a signaling device into the analysis is novel to the literature on trade and educational behavior. ${ }^{8}$

In the next section we develop a simple two-sector a model of worker educational behavior with imperfect screening of worker skills. In Section 3 we derive the autarky equilibrium with adverse selection in the labor market, and examine the relative effects of educational policies directed at altering schooling and skill acquisition behavior. In section 4 we turn to globalization policies and consider how import penetration influences educational behavior of workers. Section 5 considers the case where firms face in the skilled sector face export opportunities. In Section 6 we discuss an extension that allows for monopolistic competition in the product market and the final sections offers a conclusion.

\footnotetext{
${ }^{8}$ The interaction between trade and education has also been applied to New Growth Theories to examine the link between globalization and differences in development across countries (e.g., Wood and Ridao-Cano 1999 and Redding and Schott (2003). However, none of these models consider education a signaling device. The distinction we draw between signaling and productivity enhancing motives for education may be important to new growth theories, given the evidence in Bils and Klenow (2000) that differences in educational attainment explain little of the variation in growth rates across countries.
} 


\section{The Model}

Our model consists of two types of workers, those born with innate academic aptitude and those born without it, but this feature is private information. Prior to seeking a job, workers with academic aptitude can choose to obtain an education and become either low or high skilled, knowing that firms imperfectly screen for their productivity as skilled workers at the time of hiring. Firms must choose between the skill-intensive and unskilled sectors of the economy in which to operate, and within the skilled sector firms must select among two production technologies, which differ in skill intensity. All output is sold in perfectly competitive markets. The assumption of perfect competition is made for tractability and, more importantly, so that we can highlight the distortions generated by asymmetric information about worker skills without having to worry about how they interact with distortions tied to imperfect competition in the product market. In Section 6 we discuss how our results generalize to models with a monopolistically competitive framework.

2.1 Consumer Preferences: All consumers have identical homothetic preferences over two goods X and Y. We set $\mathrm{Y}$ as the numeraire and denote $p$ as the price of $\mathrm{X}$.

2.2 Worker Education: Each country is endowed with a measure $U$ of workers without an aptitude for education. We assume that these workers do not purchase schooling, either because they cannot earn the grades required to get into college or because they lack access to the resources needed to cover the cost of education. We classify them as unskilled workers. There is also a measure $S$ of workers that vary in aptitude, $a$, to perform in school. The frequency distribution of aptitude for these workers is $G(a)$ over $[0, \bar{a}]$ so that $G(\bar{a})=S$. Workers with an aptitude for education choose whether or not to go to school.

Unskilled workers are able to produce $Y$ but do not have the skills required to use any of the technologies available to produce $X$. In contrast, all workers born with academic aptitude are qualified to use a basic technology to produce $X$. In addition, those with aptitude who purchase schooling and exert sufficient effort to their coursework can produce $X$ using a more sophisticated technology (more details on the $\mathrm{X}$ sector technologies are provided below). Because aptitude and effort are not observable, firms using the basic technology will not be able to distinguish unskilled workers from those with aptitude 
absent any signal (i.e., a degree), and without screening firms using the more sophisticated technology will not be able to distinguish those who put in effort into their coursework from those who do not.

We assume that the cost of schooling, $C_{S}(a)$, is decreasing and convex in aptitude, and given in terms of disutility. Workers with aptitude can purchase schooling and earn a degree, regardless of the effort devoted to their coursework. Since the degree is observable schooling serves as a signaling device that allows workers with aptitude to distinguish themselves from unskilled workers. However, schooling alone does not increase productivity. Workers who put forth no effort during their education remain lowskilled workers, but those who put forth a unit of effort in school enhance their productivity and become high-skilled workers. The disutility from effort, $C_{E}(a)$, is also decreasing and convex in aptitude. We denote the endogenous mass of low-skill workers who do not put forth effort as $S_{L}$, and denote the mass of high-skill workers by $S_{H}$.

2.3 Worker Screening \& Wages: Workers signal that they attended school by showing their degree to firms, which verifies that they are not unskilled. However, the effort exerted while in school is not observable. As a result firms cannot perfectly distinguish between more productive high- skilled workers and less productive low-skilled workers upon hiring. We assume that upon the completion of schooling, workers take a test with the results observable by all firms. ${ }^{9}$ Those who pass the test reveal themselves as highly productive skilled workers and are eligible for high-skilled employment; whereas those who fail the test are classified as low-skilled applicants. High skilled workers, who exerted effort during school, pass the test with probability $\lambda \leq 1$, while any low skill worker that did not exert effort fails the screening test. Note that in the case of $\lambda=1$ the screening process is perfect, otherwise it is imprecise.

Popular examples of screening tests administered to workers upon recruitment are the Wonderlic Cognitive Ability Test or the Armed Forces Qualification Test (AFQT). For several decades the 'Wonderlic' has been a screening device used in occupations ranging from executives to general clerical

\footnotetext{
${ }^{9}$ Equivalently, we could assume that after schooling workers either pass or fail the exam regardless of which firm administers it. Thus, there would be no reason to repeat the exam. Such strategic motives would complicate our analysis by introducing another dimension of asymmetric information. Our current set-up allows us to focus on the problems caused by the fact that effort and ability are unobservable in the cleanest possible environment.
} 
work, and across many industries including healthcare, finance and even professional sports. The exam takes 12 minutes to administer and so provides a low-cost, albeit imperfect, signal of worker skills. Similarly, scores on the AFQT are often used by employers to infer potential differences in productivity among otherwise identical workers. More concretely, Lange (2007) estimates that, even though employers can learn relatively quickly about worker performance, there is still persistent expectation error after 3 years of employment; specifically his estimates imply that it takes approximately 26 years on the job to reduce expectation error about individual worker productivity to less than $10 \%$ of its initial value. In other words, the mechanisms that firms can use to screen workers are effective, yet imperfect.

Firms hire from frictionless labor markets and compensate workers based on their performance on the screening exam. Those who pass the screening exam reveal themselves as high-skill workers and are paid a wage $w_{H}$. Workers who do not pass the screening exam, either because they are low skilled or misidentified high skill workers, are each paid a wage $w_{L}$. Although firms cannot distinguish between low and high skill workers that fail the exam, the wage that they pay, $w_{L}$, will account for their differences in productivity on average. Unskilled workers are paid a wage $w_{U}$.

2.4 Labor Demand \& Production: Good Y is produced using only unskilled labor with each worker producing one unit of output. All firms producing $\mathrm{Y}$ are identical and since $\mathrm{Y}$ is the numeraire, the equilibrium unskilled wage must satisfy $w_{U}=1$. Good $X$ is produced using only skilled labor, so that workers must have a degree to be hired.

There are two technologies available that can be used to produce the skilled good. Firms are free to enter and adopt either production mode. The first technology, which we refer to as basic, allows firms to produce $X$ using low-skilled or high-skilled labor, with a low-skilled worker producing $b$ units of output and a high-skilled worker producing $\theta b$ units with $\theta>1$. However, workers produce output in teams and individual productivity is not observable - thus, all workers employed by basic firms are treated the same. Since wages are determined in a competitive market and the productivity of workers is fixed for any level of output, basic firms produce output at constant marginal cost; however they also face 
a capacity constraint of $\bar{x}_{b}$ units. The second technology, which we refer to as modern, requires highskilled labor. Each high-skilled worker can produce $h>\theta b$ units of $X$ and firms that adopt the modern technology can produce at constant marginal cost up to a capacity constraint of $\bar{x}_{m}>\bar{x}_{b}$. The capacity constraint is used to capture the notion of increasing marginal costs for the firm, and is a common device used in the industrial organization literature on Bertrand (pricing) games.

The assumptions that $h>\theta b$ and $\theta>1$ reflect the benefits of schooling and effort to worker productivity. Differences in productivity across technologies are partially offset by differences in the costs of adoption. The basic technology requires a fixed investment $F_{b}$, while the modern technology requires a cost $F_{m}>F_{b}$, each given in terms of additional units of the numeraire good that must be purchased to setup a firm. ${ }^{10}$ Our interest is in studying a menu of technologies that are skill biased: note that the assumption $h>\theta b$ also implies that high skill workers have comparative advantage using the modern technology. Moreover, it should be the case that turning one high-skill worker into a low-skill worker should increase the expected total output produced by basic firms, which will be the case if $b>(1-\lambda) \theta b$. These assumptions about the relative productivity of workers imply that the basic technology is biased toward low skill workers, while the modern technology is biased toward high skill workers. Differences in the skill intensity of modern or basic technologies, even within narrowly defined sectors, are consistent with the evidence in Doms, Dunne and Troske (1997).

Given that the modern technology requires high-skilled workers, firms that adopt this technology will only hire applicants who pass the screening exam. These firms pay a wage $w_{H}$ with each employee generating $h$ units of output; thus the marginal cost for modern firms is given by $\frac{w_{H}}{h}$. Alternatively, firms can adopt the basic technology and hire workers from the pool of low-skilled applicants. ${ }^{11}$ Without the ability to distinguish low from high-skilled workers in pool of applicants that fail the screening exam, all

\footnotetext{
${ }^{10}$ As in Helpman, Itskhoki and Redding (2010), we assume that firms cover their fixed costs by using unskilled labor (perhaps to build a plant and install capacity). This assumption does not play a critical role in our analysis. We could assume that fixed costs are covered with skilled labor (as in Yeaple 2005) without altering our results. We prefer our approach because it makes the skilled labor market clearing conditions more tractable.

${ }^{11}$ Basic firms could also choose to hire high skill workers that pass the screening exam. However, we show in the appendix that such behavior could only arise for a knife-edge set of parameters (see Result A.3 in the Appendix).
} 
workers at basic firms are paid the same $w_{L}$. The imperfect screening technology implies that there are $(1-\lambda) S_{H}$ relatively productive high-skill workers in the low-skill applicant pool who each generate $\theta b$ units of output, and $S_{L}$ available workers who produce $b$ units of X. Then, for basic firms the expected output generated by workers hired from the low-skill applicant pool is

$$
\phi \equiv \frac{b\left[S_{L}+\theta(1-\lambda) S_{H}\right]}{S_{L}+(1-\lambda) S_{H}}
$$

It follows that the marginal costs for the typical basic firm are $\frac{w_{L}}{\phi}$.

\section{Autarky}

We are now in position to describe the equilibrium conditions for our model when the economy is closed. Our derivation proceeds in reverse order of the model above: we begin with product market clearing conditions, then characterize equilibrium in labor markets, and then determine equilibrium educational behavior of workers.

3.1 Product Market Equilibrium: Free entry in the $X$ sector implies that both basic and modern firms must earn just enough profit to cover the fixed cost of adopting their technology. In the autarkic equilibrium this means that we must have

$$
\begin{aligned}
& F_{b}=\left(p-\frac{w_{L}}{\phi}\right) \bar{x}_{b} \\
& F_{m}=\left(p-\frac{w_{H}}{h}\right) \bar{x}_{m}
\end{aligned}
$$

where $p$ denotes the price of $\mathrm{X}$. Note that since price exceeds marginal cost, all firms produce at capacity. Next, if we use $N_{b}\left(N_{m}\right)$ to denote measure of firms that adopt the basic (modern) technology; and use $E$ to denote total expenditures by consumers, then equilibrium in the market for $X$ requires

$$
\bar{x}_{m} N_{m}+\bar{x}_{b} N_{b}=X(p, E)
$$

The left-hand-side of (4) gives total production while the right-hand-side is total demand for X.

3.2 Labor Market Equilibrium: We now turn to the labor markets, starting with the markets for skilled workers. Equating supply with demand for each skill level yields the following equilibrium conditions

$$
S_{L}+(1-\lambda) S_{H}=\frac{\bar{x}_{b}}{\phi} N_{b},
$$




$$
\lambda S_{H}=\frac{\bar{x}_{m}}{h} N_{m} .
$$

In (5)-(6), the left-hand-side gives the size of the skilled applicant pool for firms using the respective technology. The right-hand-side is simply the labor demand per firm times measure of firms of each type.

3.3 Equilibrium Educational Behavior: For a worker with aptitude $a$, the benefit of purchasing schooling without devoting any effort to coursework is that this qualifies them for a low-skilled job that pays $w_{L}$, as compared to taking an unskilled job that pays $w_{U}=1$. The cost of schooling to this worker is $C_{S}(a)$. Thus, if we let $a_{S}$ denote the ability level of the worker who is just indifferent between purchasing schooling and taking an unskilled job, $a_{S}$ must satisfy

$$
C_{S}\left(a_{S}\right)=w_{L}-1
$$

All workers with $a<a_{S}$ strictly prefer unskilled employment. Workers with $a \geq a_{S}$ obtain schooling and must also decide whether to devote effort to their coursework. The cost of exerting enough effort to qualify for a high-skilled job is $C_{E}(a)$ and the benefit is that doing so increases your earnings from $w_{L}$ to $w_{H}$, provided that you pass the screening test, which happens with probability $\lambda$. Thus, a worker with ability level $a_{E}$ is just indifferent between exerting a unit of effort and no effort when $a_{E}$ satisfies

$$
C_{E}\left(a_{E}\right)=\lambda\left(w_{H}-w_{L}\right)
$$

Given the distribution of worker aptitude, we can define the masses of low and high skill labor supplies using the respective cutoffs for educational behavior:

$$
\begin{aligned}
& S_{L}=G\left(a_{E}\right)-G\left(a_{S}\right) \\
& S_{H}=S-G\left(a_{E}\right)
\end{aligned}
$$

Finally, total expenditure by workers, $E$, is equal to their total income which is

$$
E=\left[S_{L}+(1-\lambda) S_{H}\right] w_{L}+\lambda S_{H} w_{H}+\left[U+S-S_{L}-S_{H}\right],
$$

where the first term is income from low-skilled employment, the middle term is income from high-skilled employment and the last term is income from unskilled employment.

3.4 Determining the Autarky Equilibrium: This simple model consists of 11 unknowns, $w_{L}, w_{H}, a_{E}, a_{S}$, 
$S_{L}, S_{H}, N_{m}, N_{b}, E, p$ and $\phi$, that define the closed economy equilibrium, which is determined by (1)-(11). Our first goal is to show that in spite of the informational asymmetries, the autarkic equilibrium is unique. Given that preferences are homothetic, we know that the relative demand curve is downward sloping in relative prices. Thus, it is sufficient to show that the relative supply curve is upward sloping.

With both types of technologies adopted in the skilled sector, the Relative Supply for goods X and $\mathrm{Y}$ for the closed economy is given by

$$
\frac{X}{Y}=\frac{\bar{x}_{b} N_{b}+\bar{x}_{m} N_{m}}{U+S-S_{L}-S_{H}-N_{b} F_{b}-N_{M} F_{M}}=\frac{b\left[\left(G\left(a_{E}\right)-G\left(a_{S}\right)\right)+(1-\lambda) \theta\left(S-G\left(a_{E}\right)\right)\right]+\left(S-G\left(a_{E)}\right) \lambda h\right.}{U+G\left(a_{S}\right)-b \frac{F_{b}}{\overline{\bar{x}}_{b}}\left[\left(G\left(a_{E}\right)-G\left(a_{S}\right)+(1-\lambda) \theta\left(S-G\left(a_{E}\right)\right)\right]-\lambda h_{\frac{M}{\bar{x}_{M}}}\left(S-G\left(a_{E}\right)\right)\right.}
$$

where the second equality follows from substituting (1), (5), (6), (9) and (10). Note that relative supply is solely as a function of $a_{S}$ and $a_{E}$, given the parameters of the model. Thus, the relative supply in (12), for a given price $p$, is determined completely by the aptitude cutoffs for schooling and skill acquisition.

To examine the relationships between the cutoffs $a_{S}$ and $a_{E}$ and relative prices we reduce the supply side of the model to two equations in two unknowns; substituting (2), (3), (5), (6), (9) and (10) into equilibrium conditions for optimal schooling and skill acquisition behavior in (7) and (8) yields

$$
\begin{aligned}
& L\left(a_{S}, a_{E}\right) \equiv C_{S}\left(a_{S}\right)-\left(p-\frac{F_{b}}{\bar{x}_{b}}\right) \phi\left(a_{S}, a_{E}\right)+1=0 \\
& H\left(a_{S}, a_{E}\right) \equiv C_{E}\left(a_{E}\right)-\lambda\left[\left(p-\frac{F_{m}}{\bar{x}_{m}}\right) h-\left(p-\frac{F_{b}}{\bar{x}_{b}}\right) \phi\left(a_{S}, a_{E}\right)\right]=0
\end{aligned}
$$

Note that the responses of the productivity of basic firms to changes in schooling and skill acquisition among the workers at the margin are given by the following the partial derivatives:

$$
\phi_{S} \equiv \frac{\partial \phi}{\partial a_{S}}=\frac{(\phi-b) g\left(a_{S}\right)}{S_{L}+(1-\lambda) S_{H}}>0 \quad \phi_{E} \equiv \frac{\partial \phi}{\partial a_{E}}=\frac{-(\theta-1)(1-\lambda) b\left(S_{L}+S_{H}\right) g\left(a_{E}\right)}{\left[S_{L}+(1-\lambda) S_{H}\right]^{2}}<0 .
$$

Equation (13) defines the ability of the marginal low-skilled worker for any given $a_{E}$. This curve is upward sloping in $\left(a_{S}, a_{E}\right)$ space for any $p$. The logic is straightforward - an increase in $a_{E}$ means that there are fewer high-skilled workers, and this lowers the average productivity for workers in the low-skill pool, $\phi$, thereby reducing the low-skill wage. With fewer high skill workers to free ride off of in the low skill labor pool, there is less incentive to acquire schooling; $a_{S}$ must rise to restore the equality in (13). 
Equation (14) defines the ability of the marginal high-skilled worker for any given $a_{S}$. This curve is also upward sloping in $\left(a_{S}, a_{E}\right)$ space and the logic is similar. An increase in $a_{S}$ means fewer lowskilled workers and this pushes up the average productivity of the low-skilled labor pool, $\phi$. Hence $w_{L}$ rises, and this reduces the relative benefit from exerting effort. As a result, $a_{E}$ must rise to restore the equality in (14). Figure 1 illustrates the two conditions characterizing equilibrium educational behavior.

There are two concerns in characterizing the autarky labor market equilibrium with imperfect screening of worker skills. First, with two upward sloping relationships that characterize schooling and skill acquisition behaviors in (13) and (14), one might expect that a given $p$ might be associated with multiple values of the cutoffs for educational behavior, $\left(a_{S}, a_{E}\right)$. However, we show in the appendix (see Result A.1) that $H(\cdot)$ is less steeply sloped than $L(\cdot)$ for any $\left(a_{S}, a_{E}\right)$. This gives us the following lemma.

Lemma 1: Any relative price level $p$ is associated with a unique pair of cutoffs in worker aptitudes, $\left(a_{S}, a_{E}\right)$, that define the mass of workers that obtain schooling and acquire high skills, respectively.

The second concern regarding multiplicity is that, even though there is a unique set of educational choices across workers for any $p$, differences in educational behavior across a range of potential prices may still cause the relative supply curve to be downward sloping, resulting in multiple equilibria. Thus, we must also be concerned with how changes in prices influence educational behavior.

Lemma 2: An increase in the relative price of the skilled good, $p$, leads to an increase in the mass of workers that obtain schooling, and an increase in the mass of workers that obtain high skills.

In order to prove Lemma 2 we must determine the impact of a change in $p$ on the educational choices of workers. To do so, we define $L_{j} \equiv \frac{\partial L}{\partial a_{j}}$ and $H_{j} \equiv \frac{\partial H}{\partial a_{j}}$ for $j=S$, E. From (13) and (14) we have

$$
\begin{array}{lll}
L_{S}=C_{S}^{\prime}\left(a_{S}\right)-\frac{W_{L}}{\phi} \phi_{S}<0 & \text { and } & L_{E}=-\frac{W_{L}}{\phi} \phi_{E}>0 \\
H_{S}=\frac{\lambda W_{L}}{\phi} \phi_{S}>0 & \text { and } & H_{E}=C_{E}^{\prime}\left(a_{E}\right)+\frac{\lambda W_{L}}{\phi} \phi_{E}<0
\end{array}
$$

For later use, we define $D \equiv L_{S} H_{E}-H_{S} L_{E}>0$, where the inequality is derived in the proof Result A.1 in the Appendix. Then straightforward differentiation of (13) and (14) yields the results we need:

$$
\frac{d a_{S}}{d p}=\frac{\phi H_{E}-\lambda(h-\phi) L_{E}}{D}<0 \quad \text { and } \quad \frac{d a_{E}}{d p}=\frac{\lambda(h-\phi) L_{S}-\phi H_{S}}{D}<0
$$


High skill workers are more productive using any technology in the skilled sector, and low skill workers are more productive than unskilled workers. Hence, the result in Lemma 2 implies that an increase in $p$ leads to an increase in the relative supply of goods. Each new worker who purchases schooling shrinks the supply of $Y$ by one unit while increasing the supply of $X$ by $b$ units; and each new worker who acquires high skills pushes $X$ up by $h-b$ if they pass the screening test and are employed by a modern firm and by $\theta b-b$ if they fail the screening test and take a job with a basic firm. Given a downward sloping demand curve, we then obtain a unique relative price level $p$, which Lemma 1 assures is associated with a unique set of educational behaviors among workers.

Proposition 1: When there are firms with heterogeneous productivities operating in the skill intensive industry, the autarky equilibrium is unique even when worker skills are not perfectly observed by firms.

Previous analyses of labor markets with adverse selection have typically found the possibility of multiple equilibria, each of which imply different worker outcomes and potentially different output prices. This multiplicity makes it difficult for the models to consistently match stylized facts about labor markets, and hinders any policy analysis. Yet, these analyses generally abstract from technological differences and open economy issues (e.g., Blankenau and Camera 2006 and Krugman 2000). An advantage of our framework is the ability to analyze worker signaling behavior via education, technological adoption and international trade simultaneously in general equilibrium framework. Moreover, we obtain a unique equilibrium when education acts to both signal skills and to enhance productivity, which encompasses a rich set of worker behaviors on the supply side of the market.

3.5 Education Policies in the Autarky Equilibrium: Policies designed to influence educational behavior are ubiquitous. The US offers the Stafford loan program to reduce to cost of borrowing funds for post-secondary educational purposes, and in 2012 updated the Workforce Investment Act to provide federal funds for job training. Other countries have similar policies that target the educational behavior individuals on the cusp on entering the workforce. Policies that change the cost of schooling obviously have an impact on worker educational behavior, but subsequent changes in technological adoption and hiring by firms imply that such policies have general equilibrium consequences. And, even though 
Proposition 1 ensures that the closed economy equilibrium is unique with imperfect screening of worker skills, the equilibrium adjustments to policy change are distorted. We close our discussion of the autarky model by examining the effects of such policies on the domestic supply of goods and on relative prices.

To clearly identify educational policies we rewrite the cost of schooling as $\eta C_{S}(a)$ and the cost of effort as $\delta C_{E}(a)$. Policies that target educational outcomes directly can then be examined by considering changes in $\eta$ and $\delta$. Consumer preferences are unaffected by educational policies, and so we need only consider how to costs of education influence the supply side of the model. Differentiating optimal educational behavior of workers in (13) and (14) for any given price level, $p$, yields

$$
\left.\frac{d a_{S}}{d \eta}\right|_{p}=\frac{-C_{S}\left(a_{S}\right) H_{E}}{D}>0 \text { and }\left.\quad \frac{d a_{E}}{d \eta}\right|_{p}=\frac{C_{S}\left(a_{S}\right) H_{S}}{D}>0
$$

A reduction in the cost of schooling induces more workers to attend school and more workers to put effort into their coursework for any given $p$. The first result follows directly from the cost reduction, whereas the second result stems from the fact that as more low aptitude workers attend school average productivity for low-skilled workers falls. This triggers a drop in $w_{L}$, which raises the expected return from effort. With $a_{E}$ and $a_{S}$ both falling, relative supply will increase - that is, a reduction in the cost of schooling shifts relative supply out to the right.

A similar analysis allows us to derive the impact of a change in the cost of effort. We obtain

$$
\left.\frac{d a_{S}}{d \delta}\right|_{p}=\frac{C_{E}\left(a_{E}\right) L_{E}}{D}>0 \quad \text { and }\left.\quad \frac{d a_{E}}{d \delta}\right|_{p}=\frac{-C_{E}\left(a_{E}\right) L_{S}}{D}>0
$$

A reduction in the cost of effort results in more students acquiring high skills. As the measure of highskill workers rises, and as some of these workers fail the screening test, productivity at basic firms increases. This triggers an increase in the low-skill wage, $w_{L}$. A higher low-skill wage induces more low aptitude workers to purchase schooling. So, just as with a reduction in the cost of schooling, lower costs of effort shift relative supply out to the right. These two sets of results imply the following result.

Proposition 2: Lower costs of schooling and effort reduce the autarkic price of the skill intensive good.

Another way to interpret the result in Proposition 2 is that educational polices that target the cost of schooling and effort can independently grant a country comparative advantage in producing skill 
intensive goods. Bougheas et al. (2011) also highlights the potential for governments to influence trade patterns through education policies, but do not suggest what market failures would justify policy intervention. Here a government may introduce policies to mitigate the problem of imperfect screening of worker skills. ${ }^{12}$ Yet, it is important to recognize that such policies can have subsequent impacts on trade patterns. In the following sections, we focus on the open economy in more detail.

\section{The Open Economy: Import Penetration}

Consumers in all countries share identical Cobb-Douglas preferences over X and Y. Hence, the only differences between the autarky and open economy models are due to the supply side of the model; in the open economy with costly trade, firms may adjust the technologies they adopt and workers may adjust their educational behavior. We consider the response of a small economy to trade openness, where the relative price is fixed on world markets at $p^{*}$. Although our primary interest is in the impact of greater export opportunities in the skill-intensive sector on educational choices, the analysis of import penetration is simpler given that import competition affects all domestic firms symmetrically, whereas export opportunities typically vary across firms of different size or productivity. Thus, in this section we first consider an economy that can import skill intensive goods from foreign firms with $p^{*}<p$. In the next section we turn to the case in which $p^{*}>p$ so that some domestic firms may want to export.

Opening the domestic market to foreign producers when $p^{*}<p$ changes relative supply for the domestic market: instead of the upward sloping curve that reflects the behavior of domestic firms, a small importing country faces a flat supply curve at $p^{*}$ as it can purchase the $X$ at the fixed world price $p^{*}$. Figure 2 illustrates the open economy equilibrium for a small importing country. The dashed line

\footnotetext{
${ }^{12}$ Rather than targeting education policies, Vogel (2007) suggests that differences in labor market institutions can interact with educational behavior in a way that influences comparative advantage. In particular, he suggests that institutions in some countries may better allow skilled entrepreneurs to manage moral hazard issues among their workforce. However, there is an important distinction between our analyses regarding the impact of asymmetric information in the labor market on relative output prices. As we discuss in detail below, imperfect screening of worker skills distorts both schooling and skill acquisition behavior; here, alleviating the information problem via better institutions (i.e., changing $\lambda$ ) may mitigate one distortion while making the other worse. As a result, the effect of changing $\lambda$ on relative prices, and the pattern of comparative advantage is generally indeterminate.
} 
represents the autarky relative supply curve, while the solid flat line at $p^{*}$ is the supply curve for the domestic market as it can purchase the skilled good from global markets.

As the home country begins to import $\mathrm{X}$, rather than buying from domestic producers, workers recognize that demand for their skills diminishes, and adjust their educational behavior accordingly. In proving Lemma 2 we derived the relationship between exogenous changes in prices and worker educational behavior. Similar adjustments take place when import penetration in the skill intensive sector reduces $p^{*}$ : that is, fewer workers will obtain schooling and fewer workers will pursue high skills. This reduction in educational attainment as the relative demand for skilled labor diminishes is consistent with the evidence in Atkin (2012); Mexican workers are more likely to drop out of secondary education when the arrival of local unskilled manufacturing employment opportunities is relatively small. ${ }^{13}$

The individual educational behavior of workers reflects their rational responses to changes in job prospects. However, in the aggregate educational choices are distorted by the imperfect screening of skills by firms. ${ }^{14}$ So the question remains whether the reduction in schooling and skill acquisition following import penetration mitigates or exacerbates these distortions. The efficient outcome for this small open economy corresponds to an equilibrium in which no information problems exist (i.e. $\lambda=1$ ). The distortions in educational behavior can then be characterized by examining deviations from the first-best outcome; that is we differentiate the equilibrium conditions in (13) and (14) with respect to $\lambda$, and consider the limiting case of full information as $\lambda$ approaches one. Differentiating we obtain

$$
\begin{aligned}
& \frac{d a_{S}}{d \lambda}=\frac{w_{L}}{D \phi}\left\{C_{e}^{\prime}\left(a_{e}\right) \phi_{\lambda}+\left(w_{H}-w_{L}\right) \phi_{E}\right\} \gtreqless 0, \\
& \frac{d a_{E}}{d \lambda}=\frac{1}{D}\left\{L_{S}\left(w_{H}-w_{L}\right)-\frac{w_{L}}{\phi} \phi_{\lambda} C_{S}^{\prime}\left(a_{S}\right)\right\}<0
\end{aligned}
$$

\footnotetext{
${ }^{13}$ As Atkin (2012) argues, the arrival of manufacturing jobs presented employment opportunities predominantly for unskilled labor, wherein $80 \%$ of workers in those positions possessed less than a high-school degree in 2000.

${ }^{14}$ A large empirical literature has documented the feature of 'over-education' in labor markets, as indicated by workers acquiring schooling in excess of what is needed to qualify for their job (see Leuven and Oosterbeek 2011 for a recent survey). Here, imperfect screening of skills may lead some high-skill workers to obtain jobs that do not fully complement their skills. We note that workers take this into account when choosing which skills to acquire.
} 
where $\phi_{\lambda} \equiv \frac{\partial \phi}{\partial \lambda}=\frac{S_{H}(\phi-b \theta)}{S_{L}+(1-\lambda) S_{H}}<0$. Equation (18) gives us one of our fundamental results - imperfect screening leads to an inefficiently low level of skill acquisition. As $\lambda$ falls below one and screening gets less precise, the return to effort, and hence skill acquisition, declines. As a result, $a_{E}$ rises and the supply of high-skilled workers falls. The effect of imperfect screening on schooling behavior is given in (17); the first term in brackets is positive while the second term is negative, indicating that imperfect screening has an ambiguous effect on the level of schooling obtained among the labor force. On one hand, as $\lambda$ falls there are fewer high-skill workers taking the screening test, and this means less free riding off of their higher productivity. On the other hand, as $\lambda$ falls the probability that a high-skilled worker will fail the test rises, and this increases the return to schooling for low-ability workers. Since these two effects work in opposite directions, the overall level of schooling purchased can generally be too high or too low. We note, however, that as $\lambda$ approaches one, $\phi_{E}$ becomes arbitrarily small. This implies that when screening is sufficiently precise, equilibrium will be characterized by over-education. Thus, we have

Proposition 3: If worker screening is imperfect, then workers will under-invest in skill acquisition. In addition, if screening is sufficiently precise, the overall workforce will over-invest in schooling.

Note that for a screening technology that is sufficiently precise, the educational behavior of workers is consistent with the criticism that too-many people go to college put forth by Berg (1970), Freeman $(1975,1976)$ and Murray (2009). Also, note that there is over-investment in schooling because the expected return to education is greater than the return for those workers who are at the margin of whether go to school. Consistent with feature, Carneiro, Heckman and Vytlacil (2011) provide evidence that average return to college is much higher than the marginal return to for workers considering whether to enroll. Furthermore, Lange (2007) shows that employers can learn about worker productivity fairly quickly, albeit with persistent asymmetric information. His estimates suggest that half the expectation error surrounding worker performance is eliminated within 3 years. Then given the additional observable information about workers, his estimates suggest that on average there is substantial information that can be screened; i.e., $\lambda$ near unity. Given this evidence, we take a sufficiently precise screening technology to be the empirically relevant case, and focus on equilibria with over-investment in schooling. 
Combining the insights from Lemma 2 and Proposition 3, we have the following result

Proposition 4: Globalization that results in greater import competition in the skill intensive sector (i) exacerbates the distortion in the investment in skills, so that fewer individuals exert effort to become high skill workers; and (ii) mitigates the distortion in the investment in schooling, so that fewer workers go to school.

Changes in educational behavior reflect the impact of import competition on relative wages. More workers will go to school as low-skill wages rise, while fewer put forth effort as high-skill wages fall. Then, given the result in Proposition 4, we can derive the implied changes in income inequality directly.

Corollary 1: Globalization that results in greater import competition in the skill intensive sector reduces wage inequality among the domestic labor force.

Formally this result is obtained from combining optimal education behavior from (7) and (8) with the relationship between relative prices and education in Lemma 2. The cost of schooling and the cost of effort for the marginal workers must both fall as relative prices fall; this can only occur if $w_{L}$ drops relative to 1 (the unskilled wage), so that low-skilled workers lose relative to unskilled workers, and if $w_{H}$ falls relative to $w_{L}$, so that high-skilled workers lose relative to low-skilled workers. Thus, wage inequality falls as the with increased import competition in the skill intensive sector.

Our results for the impact of globalization on relative wages are distinct from previous analyses in which education is a binary choice, or schooling and skill acquisition are ignored entirely. A change in wages of high skilled workers relative to low skill workers corresponds to a shift in the distribution of wages within a group of workers that have the same observed level of education, rather than across workers with different educational attainments. Lemiuex (2006a,b) documents broad evidence that recent episodes of rising wage inequality are concentrated among college educated workers, even within specific occupations and professions. He argues that an empirical model with heterogeneous returns across workers within educational groups best matches changes in the US income distribution between 1973 and 2005. Moreover, the evidence shows that while residual wage inequality increased for workers with postsecondary education, there is little change in the residual variation in wages for less educated workers. These facts are inconsistent with models that assume that workers skills are perfectly observed, or assume that education serves only a single purpose for all workers (i.e., to enhance productivity or signal ability.) 
We close this section by showing that since our model takes into account two key features of the educational process, signaling and productivity enhancement, it allows for a fairly rich analysis of education policies in an open economy. We often hear policy makers emphasize the need for a highly educated workforce as a way to ensure growth and prosperity in a globalized economy. In 2012, the US reauthorized the Workforce Investment Act (WIA), which provides federal funding for job training and employment assistance. One of the major changes made to the original WIA of 1998 is that the use of federal funds must conform to best practices (expenditures must correspond to the most effective educational programs). Moreover, the 2012 reauthorization of the WIA stipulates that measurements of effectiveness must take into account employer satisfaction of worker performance, rather than simple graduation or employment rates of participants. Therefore, it is important to understand the different incentives for workers to pursue education as policies alter the costs of obtaining skills. Our framework is ideal for this purpose. In particular, we can use the results reported in (15)-(16) to assess the relative effectiveness of various policies in reducing the distortions in educational behavior.

We have previously shown in Proposition 3 and (15)-(16) that a lack of high-skilled workers can be addressed by instituting programs that lower either the cost schooling or effort. However, in addition to the monetary cost of such programs, (15)-(16) imply that there is an additional cost - lowering these costs make the over-education distortion worse. Thus, the relative effectiveness of these programs depends on the size of the benefit (i.e., the increase in the size of the high-skill workforce), relative to size of the new distortion created (i.e., the resulting increase in the measure of workers going to school).

To compare educational policies, we define $B_{\delta}$ and $B_{\eta}$ as the reduction in $a_{E}$ brought about by a marginal reduction in the cost of effort and schooling, respectively (the "B" is used to denote "benefit" of more workers becoming high skilled). From (15) and (16) we have

$$
B_{\eta}=\frac{H_{S}}{D} \quad \text { and } \quad B_{\delta}=\frac{-L_{S}}{D}
$$

Comparing we see that $B_{\delta}>B_{\eta}$, since $-C_{S}^{\prime}\left(a_{S}\right)>0>(\lambda-1) \frac{w_{L}}{\phi} \phi_{S}$. Thus, the benefit from lowering the cost of effort is greater than the benefit from lowering the cost of schooling by the same amount. 
We next want to compare the distortions generated by the fall in $a_{S}$ triggered by the lower education costs. From (15) and (16), the decreases in $a_{S}$ due to a marginal reduction in the costs of schooling and effort, respectively, are given by $D_{\eta}$ and $D_{\delta}$ where

$$
D_{\eta}=\frac{-H_{E}}{D} \quad \text { and } \quad D_{\delta}=\frac{L_{E}}{D}
$$

Comparing the distortions we see that $D_{\delta}<D_{\eta}$ if $-C_{E}^{\prime}\left(a_{E}\right)>(\lambda-1) \frac{w_{L}}{\phi} \phi_{E}$, which always holds for $\lambda$ close to one. It follows that if screening is sufficiently precise, then the benefit of reducing the cost of effort exceeds the benefit from reducing the cost of schooling while also generating a smaller distortion. ${ }^{15}$

Proposition 5: If screening is sufficiently precise, then education policies that reward effort are superior to those that lower the cost of schooling.

There are several educational programs that are designed to limit the costs of either schooling or effort. For example, in the US the federal Stafford Loan Program provides lending at subsidized rates to students enrolled in accredited post-secondary education institutions. While the availability of lending is partly intended to ease credit constraints, an issue we do not focus on here, the facts that the interest payments are deductible from income taxes and that the rates are subsidized both imply that the program lowers the costs of schooling. On the other hand, a growing educational program called 'Flip Courses' directly targets the costs to students of putting forth effort. ${ }^{16}$ Flipped courses take advantage of internet technology by having students watch pre-recorded lectures on the appropriate subject materials at a time convenient to them. Students then attend classes where the instructor gives individual attention to students about the questions they have from the lectures and leads interactive discussion of the materials. Proponents of 'Flip Courses’ often argue that, by making lectures available online and making instructors more available to individual students, they allow students to potentially keep a job, manage family life

\footnotetext{
${ }^{15}$ We can push this further by noting that from (17) in an over-education equilibrium $-C_{E}^{\prime}\left(a_{E}\right)>\left(w_{H}-w_{L}\right) \frac{\phi_{E}}{\phi_{\lambda}}$.
} Thus, a sufficient condition for policies that lower the cost of effort to be superior to those that lower the cost of schooling is $\left(w_{H}-w_{L}\right) \frac{\phi_{E}}{\phi_{\lambda}}>(\lambda-1) \frac{w_{L} \phi_{E}}{\phi}$, or, $\frac{\lambda}{1-\lambda} \frac{w_{H}-w_{L}}{w_{L}}>-\frac{\phi_{\lambda}}{\phi} \lambda$. The right-hand-side of this condition is the elasticity of labor productivity at basic firms with respect to $\lambda$, which converges to zero as $\theta$ converges to one (this follows from the fact that $\phi_{\lambda} \equiv \frac{\partial \phi}{\partial \lambda}=\frac{S_{H}(\phi-b \theta)}{S_{L}+(1-\lambda) S_{H}}$; when $\lambda=1$, we have $\phi=b$ so that $\phi_{\lambda}=0$ ). Thus, Proposition 5 also holds if the productivity difference between high and low-skill workers for by basic firms is sufficiently small. ${ }^{16}$ For a brief introduction and discussion of Flip Courses see "Flipping the Classroom" in the Economist (9/17/11). 
and promote student engagement. In other words, these types of programs reduce the opportunity cost of effort in school. Of course, development of online course content requires funding. The WIA also provides federal funding for initiatives to develop online job training services to facilitate student performance. The result in Proposition 5 states that policies that fund programs like 'Flip Courses,' which target the costs of effort, are more effective in alleviating the adverse selection problems in the labor market than polices that provide funds to individuals to simply obtain schooling.

\section{The Open Economy: Export Activity}

We now turn to our main concern: the impact of increased export activity in the skill intensive sector on educational behavior. We now assume that $p^{*}>p$, so that domestic firms have an incentive to sell the skill intensive good to foreign consumers. Export activities differ from import competition in that it is typically the case that only a few firms export, while all firms in an industry face increased competition from greater import penetration. As is the standard approach, we assume that there is a fixed cost $F_{x}$ of accessing world markets that must be paid to begin exporting. Modern firms that export gain $\left(p^{*}-p\right) \bar{x}_{m}$ by selling to foreign consumers, while basic firms gain $\left(p^{*}-p\right) \bar{x}_{b}$. The difference in capacity constraints implies that modern firms have a stronger incentive to export. There are three possible types of equilibrium that involve a positive level of export activity:

(a) $\left(p^{*}-p\right) \bar{x}_{m}=F_{x}$

In this case, modern firms are indifferent between exporting and selling domestically. No basic firms export.

(b) $\left(p^{*}-p\right) \bar{x}_{m}>F_{x}>\left(p^{*}-p\right) \bar{x}_{b} \quad$ In this case, all modern firms export but no basic firms export.

(c) $\left(p^{*}-p\right) \bar{x}_{b}=F_{x}$

In this case, all modern firms export and basic firms are indifferent between exporting and selling domestically.

When modern firms are indifferent between exporting and not exporting, an endogenously determined fraction of them will choose to sell to foreign consumers with the remaining firms serving the domestic market. Likewise, if basic firms are indifferent between domestic and foreign markets, the fraction of firms serving each destination will be endogenously determined. Although exporting firms are more productive on average, there is significant overlap in the observed productivities of exporters and non- 
exporters; see Bernard et al. (2003). Such overlap with exporters being more productive on average is consistent with cases (a) and (c) above. In case (b), all exporters exhibit greater productivity that all domestic firms. Perhaps more importantly, the distinction between each type of equilibrium allows us to characterize the impact of export activity on educational behavior along the extensive margin; i.e., as more or fewer firms choose to export. In a type (a) equilibrium, a relatively small fraction of firms export as compared to type (b) equilibrium, while even more firms are engaged in exporting in a type (c) equilibrium. We show that the extent of firms that actively export is one key to determining how workers respond when making skill acquisition decisions. The different implications of few or many firms within an industry exporting are of particular interest because this extensive margin is an observable characteristic that varies across industries and countries, and so provides a potential strategy to identify the impact of trade on education when worker skills are imperfectly screened.

It will be convenient to derive the conditions that characterize educational behavior in each type of exporting equilibrium before we analyze the impact of trade liberalization. We turn first to the case were some modern firms export, while all basic firms sell domestically.

5.1.1 Modern Firms Indifferent between Foreign and Domestic Market: Modern firms will split across serving either the domestic or foreign market if $p=p^{*}-\frac{F_{x}}{\bar{x}_{m}}$. We denote the fraction of modern firms that export as $\gamma_{m}$. The productivity of basic firms is the same as in the autarky equilibrium, and again free entry drives profits to zero for all firms in the domestic market. However, there is an additional free entry condition for modern firms requiring that those that export also earn zero profits in equilibrium:

$$
F_{m}+F_{x}=\left(p^{*}-\frac{w_{H}}{h}\right) \bar{x}_{m} .
$$

With a fraction of modern firms exporting their output, there is a smaller supply of $\mathrm{X}$ available to the domestic market. The product market clearing condition in (4) must be adjusted to account for this fact, with the new market clearing condition given by

$$
\left(1-\gamma_{m}\right) \bar{x}_{m} N_{m}+\bar{x}_{b} N_{b}=X(p, E) \text {. }
$$

The definition of $E$ in (11), along with (4a), allows us to solve for $\gamma_{m}$, given supply-side behavior. 
Our interest here is to derive the impact of exporting activity on worker educational choices. Regardless of the differences in the prices between foreign and domestic markets, workers make educational decisions based on relative wages. Of course global opportunities impact wage rates as some firms begin to sell output abroad. As before, we can reduce the supply-side of the model to two equations in two unknowns $\left(a_{E}, a_{H}\right)$, which fully characterized educational behavior among the labor force in the open economy. Using the new free entry condition in (21), along with the free entry conditions in (2) and (3) and the worker indifference conditions in (7) and (8), it is straightforward to derive the counter-parts to equations (13) and (14) in the case in which some modern firms choose to export:

$$
\begin{aligned}
& L^{a}\left(a_{S}, a_{E}\right) \equiv C_{S}\left(a_{S}\right)-\left(p^{*}-\frac{F_{b}}{\bar{x}_{b}}-\frac{F_{x}}{\bar{x}_{m}}\right) \phi\left(a_{S}, a_{E}\right)+1=0, \text { and } \\
& H^{a}\left(a_{S}, a_{E}\right) \equiv C_{E}\left(a_{E}\right)-\lambda\left[\left(p^{*}-\frac{F_{m}+F_{x}}{\bar{x}_{m}}\right) h-\left(p^{*}-\frac{F_{b}}{\bar{x}_{b}}-\frac{F_{x}}{\bar{x}_{m}}\right) \phi\left(a_{S}, a_{E}\right)\right]=0 .
\end{aligned}
$$

5.1.2 Modern firms export while domestic firms do not export: Modern firms never choose to serve the domestic market and basic firms never export if $\left(p^{*}-p\right) \bar{x}_{m}>F_{x}>\left(p^{*}-p\right) \bar{x}_{b}$. In this case, the free entry condition for exporting modern firms in (21) simply replaces the autarky free entry condition in (3). The market clearing condition for output must again be adjusted to accommodate the fact that no modern firm sells to domestic consumers. In a type (b) equilibrium it must be that

$$
\bar{x}_{b} N_{b}=X(p, E)
$$

so that domestic supply and demand are equal. The remaining equilibrium conditions are defined just as under autarky. Reducing the supply-side of the model to two equations yields

$$
\begin{aligned}
& L^{b}\left(a_{S}, a_{E}\right) \equiv C_{S}\left(a_{S}\right)-\left(p-\frac{F_{b}}{\bar{x}_{b}}\right) \phi\left(a_{S}, a_{E}\right)+1=0, \text { and } \\
& H^{b}\left(a_{S}, a_{E}\right) \equiv C_{E}\left(a_{E}\right)-\lambda\left[\left(p^{*}-\frac{F_{m}+F_{x}}{\bar{x}_{m}}\right) h-\left(p-\frac{F_{b}}{\bar{x}_{b}}\right) \phi\left(a_{S}, a_{E}\right)\right]=0 .
\end{aligned}
$$

5.1.3 Basic Firms Indifferent between Foreign and Domestic Market: If any basic firm exports, then the relatively more productive modern firms will find export opportunities more valuable, and so they will serve only foreign markets. Basic firms are indifferent between exporting and serving the domestic market if $\left(p^{*}-p\right) \bar{x}_{b}=F_{x}$. In this case, the free entry condition and market clearing condition must again 
be adjusted from those under autarky. We denote the fraction of basic firms that export under a type (c) equilibrium as $\gamma_{b}$. With only a fraction of basic firm selling domestically, and all modern firms exporting, the domestic market clearing condition is

$$
\left(1-\gamma_{b}\right) \bar{x}_{b} N_{b}=X(p, E) \text {. }
$$

For basic firms that export there is still free entry, so profits are driven to zero such that

$$
F_{b}+F_{x}=\left(p^{*}-\frac{w_{L}}{\phi}\right) \bar{x}_{b}
$$

The remaining free entry conditions are (2), which must hold for basic firms that sell domestically, and (21), which must hold for modern firms. As before, the supply-side can be reduced to two equations that define the cutoff values $a_{S}$ and $a_{E}$. The counterparts to (13) and (14) for a type (c) equilibrium are

$$
\begin{aligned}
& L^{c}\left(a_{S}, a_{E}\right) \equiv C_{S}\left(a_{S}\right)-\left(p^{*}-\frac{F_{b}+F_{x}}{\bar{x}_{b}}\right) \phi\left(a_{S}, a_{E}\right)+1=0, \text { and } \\
& H^{c}\left(a_{S}, a_{E}\right) \equiv C_{E}\left(a_{E}\right)-\lambda\left[\left(p^{*}-\frac{F_{m}+F_{x}}{\bar{x}_{m}}\right) h-\left(p^{*}-\frac{F_{b}+F_{x}}{\bar{x}_{b}}\right) \phi\left(a_{S}, a_{E}\right)\right]=0 .
\end{aligned}
$$

5.2 Relative Supply with Export Activity: Figure 3 illustrates the relative supply curve for a small country with the potential to export skill intensive goods. The dashed line indicates relative supply under autarky. In the case where the $p$ is above $p^{*}-\frac{F_{x}}{\bar{x}_{m}}$ no firm exports, and the domestic supply is the same as under autarky. As $p$ decreases, modern firms become indifferent between exporting and serving the domestic market. The flat portion of relative supply is where $p=p^{*}-\frac{F_{x}}{\bar{x}_{m}}$, corresponding to type (a) equilibria. The intersection of relative demand curve for domestic consumers along the flat portion of the supply curve determines the fraction of modern firms that export. At lower $p$, between $p^{*}-\frac{F_{x}}{\bar{x}_{m}}$ and $p^{*}-\frac{F_{x}}{\bar{x}_{b}}$, all modern firms export and all basic firms serve the domestic market. The upward sloping portion of the relative supply curve at these price levels corresponds to type (b) equilibria. In this region, higher prices induce more basic firms to enter and sell domestically, regardless of the adverse selection problem. As $p$ drops to $p^{*}-\frac{F_{x}}{\bar{x}_{b}}$, basic firms become indifferent between serving the domestic and foreign markets. The flat portion of relative supply at this lower price level corresponds to the type (c) equilibria. 
In this case, the share of basic firms that export depends on the size of domestic demand - that is, the intersection of the relative demand curve on the flat portion of supply pins down $\gamma_{b}$. Note that in Figure 3 we have illustrated demand conditions such that a type (a) equilibrium occurs.

5.3 Export Activity, Educational Behavior \& Inequality: We are now in a position to investigate how the export behavior of domestic firms influences the decision of workers to obtain schooling and the decision of workers to acquire highly productive skills. We focus on the effects of trade liberalization characterized by a reduction in the costs to access foreign markers, $F_{x}$. To highlight the differential impacts of export activity on educational behavior as the extent of export participation varies, we begin by comparing the extreme cases (a) and (c), where relatively few or many firms serve foreign markets.

We begin by noting that in cases (a) and (c) the domestic price $p$ is completely determined by $p^{*}, F_{x}$ and the capacity constraints so that it is independent of $\lambda$. This feature makes cases (a) and (c) more tractable than case (b). In addition, since the proportion of firms that export is one of the keys to determining how workers respond when making skill acquisition decisions, and since this variable is at its extremes in cases (a) and (c), we focus our attention to these two cases. In Section 6 we extend our model to allow for monopolistic competition between firms, so that prices will be determined endogenously as in case (b). Given that incorporation of monopolistic competition also allows for relevant features such as intra-industry trade, endogenous firm size and product variety, our discussion of the case endogenously determined prices - as in (b) - is better left to that section.

In a type (a) equilibrium in which a fraction of the modern firms export, then the cutoff values $a_{S}$ and $a_{E}$ are determined by (13a) and (14a). Differentiating yields

$$
\begin{aligned}
& \frac{d a_{S}}{d F_{x}}=\frac{1}{D}\left\{-\frac{\phi}{\bar{x}_{m}} H_{E}+\frac{\lambda(h-\phi)}{\bar{x}_{m}} L_{E}\right\}>0 \\
& \frac{d a_{E}}{d F_{x}}=\frac{1}{D}\left\{\frac{\phi}{\bar{x}_{m}} H_{S}-\frac{\lambda(h-\phi)}{\bar{x}_{m}} L_{S}\right\}=\frac{1}{D \bar{x}_{m}}\left\{-C_{S}^{\prime}\left(a_{S}\right)+\frac{\lambda h w_{L}}{\phi} \phi_{S}\right\}>0
\end{aligned}
$$

Falling trade costs benefit modern firms that are exporting and initially they earn higher profits. As new modern firms subsequently enter, the demand for high skill workers rises, and so does the high skill wage. 
Anticipating better employment opportunities, more students choose to exert effort, which increases the measure of workers that become highly skilled.

Intuitively, a larger pool of high skilled workers also increases the measure of workers who fail the screening test, causing the average productivity of basic firms to rise. In addition, as more modern firms export, the supply of $\mathrm{X}$ to the domestic market falls, triggering an increase in the domestic price. These two effects both cause new basic firms to enter, which increases demand for low skill workers. As low skill wages rise, more workers find it optimal to obtain schooling. Equilibrium is reestablished when $p$ rises enough to make modern firms indifferent between exporting and selling their goods domestically.

Next consider the case in which there are many firms involved in export activities. In a type (c) equilibrium firms using either technology may export, with basic firms indifferent between selling domestically and abroad. Thus, falling trade costs enlarge the market for all firms. To determine the impact of trade on educational choices we differentiate (13c) and (14c) and obtain

$$
\begin{aligned}
& \frac{d a_{S}}{d F_{x}}=\frac{1}{D}\left\{-\frac{\phi}{\bar{x}_{b}} H_{E}+\lambda\left(\frac{h}{\bar{x}_{m}}-\frac{\phi}{\bar{x}_{b}}\right) L_{E}\right\}=\frac{1}{D}\left\{-\frac{\phi}{\bar{x}_{b}} C^{\prime}{ }_{E}+\lambda \frac{h}{\bar{x}_{m}} L_{E}\right\}>0, \text { and } \\
& \frac{d a_{E}}{d F_{x}}=\frac{1}{D}\left\{-\frac{\phi}{\bar{x}_{b}} H_{S}+\lambda\left(\frac{h}{\bar{x}_{m}}-\frac{\phi}{\bar{x}_{b}}\right) L_{S}\right\}=\frac{1}{D}\left\{-\lambda\left(\frac{h}{\bar{x}_{m}}-\frac{\phi}{\bar{x}_{b}}\right) C_{S}^{\prime}+\frac{\lambda W_{L}}{\phi} \phi_{S}\right\} .
\end{aligned}
$$

Equation (27c) indicates that a reduction in trade costs results in more workers purchasing schooling. As more basic firms begin exporting, new basic firms must then enter to serve the domestic market, and this increases the demand for low-skilled labor, pushing up $w_{L}$. Intuitively, better employment opportunities then increase the measure of workers that pursue schooling.

Equation (28c) indicates that the impact on skill acquisition is unclear. To see why, note that in case (c) skilled wages are fixed at $w_{H}=\left(p^{*}-\frac{F_{m}+F_{x}}{\bar{x}_{m}}\right) h$ and $w_{L}=\left(p^{*}-\frac{F_{b}+F_{x}}{\bar{x}_{b}}\right) \phi$. As $F_{x}$ falls, there are two effects. First, since all firms benefit from lower trade costs, both $w_{L}$ and $w_{H}$ rise. The high-skill wage rises at rate $\frac{h}{\bar{x}_{m}}$, and, holding $\phi$ fixed, $w_{L}$ rises at rate $\frac{\phi}{\bar{x}_{b}}$. If $\frac{h}{\bar{x}_{m}}>\frac{\phi}{\bar{x}_{b}}$ then $w_{H}-w_{L}$ increases, and since the return to effort is tied to this difference, more workers put in effort while in school. This effect is captured by the first term on the right-hand-side of (28c). However, as more low-ability workers 
purchase schooling, $\phi$ starts to fall and this puts downward pressure on $w_{L}$. This effect, which is captured by the second term on the right-hand-side of (28c), increases the return to effort. ${ }^{17}$

Both effects work in the same direction if $\frac{h}{\bar{x}_{m}}>\frac{\phi}{\bar{x}_{b}}$; but the overall impact on skill acquisition is uncertain if the inequality is reversed. It is worth noting that $\frac{\bar{x}_{m}}{h}$ and $\frac{\bar{x}_{b}}{\phi}$ are the labor demands for modern and basic firms, respectively. Since more productive firms tend to be larger, this suggests that the empirically relevant case is $\frac{h}{\bar{x}_{m}}<\frac{\phi}{\bar{x}_{b}}$. Also note that when the screening technology is sufficiently precise, $\phi_{S}$ approaches zero, limiting any upward pressure on the incentives to obtain high skills as trade barriers fall. In other words, when there is extensive export activity across firms, trade liberalization is likely to reduce the measure of workers that acquire high skills. The following two propositions summarize the differential effects of export activity as the extent of firms serving foreign markets varies, given that modern firms are relatively larger than modern firms.

Proposition 6: Suppose that $p^{*}>p$ and that in the initial equilibrium only some modern firms export. Then if the cost of exporting falls then the measure of workers that obtain schooling and the measure of workers that acquire high skills both increase.

Proposition 7: Suppose that $p^{*}>p$ and that in the initial equilibrium both modern and basic firms are engaged in export activity. Then if the cost of exporting falls, the measure of workers that obtain schooling increases. Moreover, if labor demand for each modern firm exceeds labor demand for each basic firm, then for a sufficiently precise screening technology, the measure of workers that acquire high skills falls.

The impact of falling trade costs on the decision to acquire schooling as described in Propositions 6 and 7 is the same for all possible equilibrium types, ${ }^{18}$ and matches the empirical evidence for the consequences of trade liberalization. Atkin (2012) finds robust evidence of greater schooling among workers across cohorts of Mexican students as skilled employment opportunities in export sectors grow.

\footnotetext{
${ }^{17}$ Note that this indirect effect is not present if $\theta=1$, since low-skill productivity would then be fixed at $b$; in such a case $H_{S}=0$ and the first term on the right-hand-side of (28c) vanishes.

${ }^{18}$ A similar adjustment takes place in the stark case where all modern firms export and all basic firms serve the domestic market. In a type (b) equilibrium, as $F_{x}$ falls the profits that modern firms earn from exporting increases and this leads to entry. As $w_{H}$ is bid up, more workers put in effort while in school, shrinking the low-skill labor pool. This creates excess demand for low-skill labor, which causes $w_{L}$ to rise. As a result fewer firms adopt the basic technology. With less output available for the domestic product market, $p$ must rise to restore equilibrium. Finally, the increase in $p$, along with a larger pool of high-skill labor, results in more workers purchasing schooling.
} 
As he argues, the educational behavior of workers as export opportunities change reflects shifts in the expected labor market outcomes across educational attainments. This is precisely the mechanism at play here. Greater export opportunities in the skilled sector always lead to an increase in relative prices, which generates entry and bids up wages for workers who attend school.

We are interested not only in how worker educational behavior adjusts to changes in export activity, but whether such changes eliminate the distortions present when firms imperfectly screen worker skills. Again, we will consider differences in the extent of export activity across firms. Note that in cases (a) and (c) the domestic price $p$ is completely determined by $p^{*}, F_{x}$ and the capacity constraints across firms. Thus, small changes in $\lambda$ do not alter prices in cases (a) and (c), and so the distortions in educational behavior described in (17) and (18) continue to apply. As we have argued above, the case where the screening technology is precise is consistent with the popular criticism of too many workers going to school, the evidence that the returns to college at the margin are well below average returns, and the direct evidence in Lange (2007) that effective screening of workers occurs quite fast. Moreover, the stylized fact common across many countries and industries is that more productive firms tend to be relatively large. Thus, for the empirically relevant parameter restrictions, such that the screening technology is sufficiently precise and modern firms are relatively large, trade liberalization has the following consequences:

Corollary 2: (i) If only some modern firms export, then a reduction in the cost of exporting exacerbates the schooling distortion and mitigates the distortion in skill acquisition behavior.

(ii) When both modern and basic firms engage in export activity and labor demand for each modern firm exceeds labor demand for each basic firm, a reduction in the cost of exporting exacerbates the distortions in both schooling and skill acquisition behavior.

Regardless of the distortion surrounding educational behavior, workers choose to go to school and to acquire skills in anticipation of the wages they expect to earn as export opportunities in the skilled sector change. Thus, we can map the endogenous changes in worker educational behavior directly to their expected wage outcomes.

Corollary 3: (i) A reduction in the cost to access foreign markets always benefits low-skill wages relative to unskilled wages.

(ii) If only some modern firms export, a reduction in the cost to access foreign markets benefits high-skilled workers relative to low-skilled workers, so that inequality rises. 
(iii) If both modern and basic firms engage in export activity and labor demand for each modern firm exceeds labor demand for each basic firm, a reduction in the cost to access foreign markets benefits low-skill worker relative to high-skill workers.

Generally, Corollary 3 states that globalization has a non-monotonic impact on wage inequality. Helpman, Itskhoki and Redding (2010) and Egger and Kreickemeier (2012) have also emphasized the potential for globalization to increase or decrease wage inequality, depending on the extent to which markets are integrated. In our framework the forces that drive these results are different, as are the implications. Reductions in the cost of exporting benefit modern firms disproportionally when only a small fraction of firms export. And, since these are the firms that primarily employ high skilled workers, high skilled workers benefit the most from globalization. Low-skilled workers free ride off of the increased effort by high-ability students, and they gain at the expense of unskilled workers. However, when a large fraction of firms export, reductions in the cost of exporting lead basic firms to increase export activity. New basic firms must then enter to pick up the slack in the domestic product market. When the fraction of firms that export is relatively high, the biggest beneficiaries of globalization are those employed by basic firms - that is, workers in the middle of the income distribution.

The wage effects described in Corollary 3 are also distinct in that export activity implies changes in inequality both within and across groups. High and low skill workers are observationally equivalent, so that an increase in $w_{H}$ relative to $w_{L}$ corresponds to an increase in residual wage dispersion among skilled workers, while changes in skilled wages relative to the unskilled wage correspond to shifts in inequality across skill groups. Notably, Card and Lemieux (1996) highlight that recent changes both the within and across skill group components of the wage distribution are substantial. Lemiuex (2006a,b) documents broad evidence that recent episodes of rising wage inequality are concentrated among college educated workers, even within specific occupations and professions. He argues that an empirical model with heterogeneous returns across workers within educational groups best matches changes in the US income distribution between 1973 and 2005. Moreover, the evidence shows that while residual wage inequality increased for workers with post-secondary education, there is little change in the residual variation in 
wages for less educated workers. These features are consistent the results in Corollary 3 where skilled workers are not able to perfectly distinguish themselves on the labor market. These facts, however, are inconsistent with models that assume that workers skills are perfectly observed, or assume that education serves only a single purpose for all workers (i.e., solely to enhance productivity or signal ability).

\section{Monopolistic Competition}

Up to this point we have assumed perfectly competitive product markets. While this assumption allows us to isolate the labor market distortions resulting from imperfect screening of worker skills, it has also required us to impose assumptions about the relative sizes of firms with differing productivities. In this section we show how the basic model can flexibly be extended to incorporate monopolistic competition between firms, so that firm sizes are determined endogenously. Although the extension is straightforward, the model does not yield analytic solutions. Therefore we impose additional structure on preferences, the underlying distribution of worker ability, and the relative productivities of each technology in order to solve the extended model numerically. We then use the numerical solutions to verify that the robustness of our results derived in the baseline model. The extension to monopolistic competition also allows us to highlight that it is indeed the relative share of domestic firms engaged in the global economy that influences how worker educational behavior adjusts to trade liberalization, rather that the composition of trade within versus across industries.

As is, Yeaple (2005) we assume that preferences over $\mathrm{X}$ and $\mathrm{Y}$ are Cobb-Douglas with $\beta$ denoting the fraction of income devoted to $\mathrm{X}$, and that $\mathrm{X}$ is a composite differentiated good produced in a monopolistically competitive market with $X=\left[\int x(i)^{\alpha} d i\right]^{\frac{1}{\alpha}}$, where $i$ indexes variety and $\sigma=\frac{1}{1-\alpha}>1$ denotes the elasticity of substitution across varieties. Given this set-up, the iso-elastic demand for variety $i$ is given by $x(i)=\left(\frac{\beta E}{P_{x}}\right)\left(\frac{p(i)}{P_{x}}\right)^{-\sigma}$, where $P_{x}$ is the price index for $\mathrm{X}$. For profit maximization, all firms charge a price that is a fixed mark-up $\left(\frac{\sigma}{\sigma-1}\right)$ over marginal cost, such that prices for basic firms and modern firms are $p_{b}=\frac{\sigma W_{L}}{(\sigma-1) \phi}$ and $p_{m}=\frac{\sigma W_{H}}{(\sigma-1) h}$, respectively. The corresponding price index is given by 
$P_{X}=\left\{N_{b} p_{b}^{1-\sigma}+N_{m} p_{m}^{1-\phi}\right\}^{\frac{1}{1-\sigma}}$. It follows immediately that profits are then $\pi_{b}=\left[\frac{\sigma W_{L}}{(\sigma-1) \phi P_{x}}\right]^{1-\sigma} \frac{\beta E}{\sigma}$ and $\pi_{m}=\left[\frac{\sigma W_{H}}{(\sigma-1) \mathrm{h} P_{x}}\right]^{1-\sigma} \frac{\beta E}{\sigma}$. Setting these profits equal to the fixed costs of entry gives us the two free entry conditions that replace (2) and (3) in the baseline model. As for the labor market, labor demand for each firm is given by demand, $x(i)$, divided by productivity; thus, the labor market clearing conditions in (5) and (6) become $S_{L}+(1-\lambda) S_{H}=\frac{x(b) N_{b}}{\phi}$ and $\lambda S_{H}=\frac{x(m) N_{m}}{h}$, respectively. Finally, in solving the model we assume that the distribution of aptitude $a$ is uniform on $[0, S]$.

To motivate trade, we assume that we have two countries that are identical in all aspects except for trade costs. Firms in the home country face a fixed cost of $F_{X}$ to export while those in the foreign country face a analogous cost of $F_{X}^{*}$. We assume that $\mathrm{Y}$ is a non-traded good, so that all trade takes place in terms of varieties of $\mathrm{X}$ (i.e., intra-industry trade). Note that an increase in import penetration corresponds to a reduction in $F_{X}^{*}$, while greater export opportunities are generated by reductions in $F_{X}$.

Although the structure of the model here is quite similar to the case of perfectly competitive product markets, there are two key differences. First, in the perfectly competitive model all product market adjustment takes place via entry and exit of firms of different types given output per firm is fixed. In contrast, with monopolistic competition we get adjustments in firm size as well as entry and exit. Second, since firms will always serve their home market under monopolistic competition, we get a type (d) equilibrium that occurs if all trade costs are sufficiently low in which all firms export.

Our goal is to determine if the comparative static properties of the perfectly competitive model carry over to this alternative framework. As with the competitive model we find that increased import penetration always trigger reductions in the measures of workers who put forth effort to acquire high skills. Correspondingly, reductions in $F_{X}^{*}$ always reduces wage inequality both within and across educational groups. As $F_{X}^{*}$ falls more imports flow into the home market and the increased competition lowers the profits firms earn from domestic sales, with modern firms suffering more severely since they produce relatively more output; i.e., both types of firms exit with a disproportionate amount of the exit 
coming from modern firms. The result is that both skilled wages fall relative to unskilled wages, and the gap between the high and low skill wages shrinks.

Similarly, increased export activity has the same qualitative effect on education decisions and inequality as in the perfectly competitive framework in that it (i) always induces more workers to purchase schooling; (ii) always increases inequality between unskilled and low skilled workers; (iii) has a non-monotonic effect on skill acquisition with more workers acquiring high skills when export activity is limited to modern firms and fewer workers acquiring skills when all firms are engaged in exporting; and (iv) has a non-monotonic effect on wage inequality between low and high-skilled workers. In addition, adjustments to changes in trade costs in type (b) equilibria are identical to what takes place in our baseline model. As trade costs fall, new modern firms enter and existing modern firms increase the amount that they ship to the foreign market. This pushes up the demand for high-skill workers, causing $w_{H}$ to rise and triggering an increase in the price that modern firms charge in their home market. The increase in $p_{m}$ shifts domestic demand towards the varieties produced by basic firms, and this causes new basic firms to enter. In the end, we get entry by both types of firms and increases in both skilled wages with $w_{H}$ rising more than $w_{L}$.

The key difference between the two models is associates with adjustment in type (a) and (c) equilibria, where some firms go from serving only their domestic market to suddenly exporting as well. In a type (a) equilibrium a reduction in $F_{X}$ causes some modern firms to start exporting. As they do, their demand for high-skill labor takes a discrete jump up and this pushes up $w_{H}$. However, in a type (a) equilibrium some modern firms serve only the domestic market and these firms are harmed by the increase in the high-skill wage. Thus, some of the modern firms that were serving the domestic market exit, a feature that does not arise under perfect competition. Reduced competition in the home market allows the remaining non-exporting modern firms to continue to break-even. The reduction in home market competition also triggers entry by basic firms, just as it does under perfect competition. Despite the different adjustment paths, in the end the fundamentals are affected just as they are in the baseline 
model: more output is produced by both types of firms with the share of output produced by modern firms increasing and $w_{H}$ increasing more than $w_{L}$.

Adjustment within a type (c) equilibrium is analogous to a discrete jump in the demand for lowskilled labor that comes about as new basic firms start to export causing some non-exporting basic firms to exit. Note that such exit by basic firms does not occur in the baseline model and it has two important implications. First, it softens the increase in $w_{L}$ that would occur without exit, and second it triggers additional entry by new modern firms, putting additional upward pressure on $w_{H}$. As a result, in terms of educational behavior and wages, the comparative statics properties for case (c) are similar to those in cases (a) and (b) - lower trade costs result in more schooling and effort and greater wage inequality between high and low-skill workers. It is not until we move to case (d), in which all firms export, that we get the non-monotonic results that are consistent with case (c) under perfect competition. That is, in case (d), as trade costs fall there is a disproportionate amount of entry by basic firms and this triggers a reduction in skill acquisition and a reduction in inequality among educated workers.

In Figure 4 we plot labor market outcomes obtained from numerical solutions to the model across various levels of trade costs. In panel A of Figure 4, we see the non-monotonic effect of changes in trade costs on skill acquisition, corresponding to differential effects of trade liberalization across equilibrium types. At high levels of trade costs (where only a few modern firms export) marginal reductions in trade costs induce more workers to become high skilled, while at low levels of trade costs (where many firms export) trade liberalization reduces the number of high skilled workers. Panel B likewise illustrates the non-monotonic effect of changes in trade costs on wage dispersion among educated workers. ${ }^{19}$

\section{Conclusions}

Is education the key to success for workers in an increasingly global economy? How much should workers invest in education? Should governments encourage the pursuit of skills as trade barriers fall? These broad economic questions can be difficult to answer given the complexities of the educational process and the myriad of incentives that workers face prior to entering the labor force. Workers can use

\footnotetext{
${ }^{19}$ The details of the numerical exercises are relegated to a technical appendix that is available on request.
} 
educational opportunities to qualify for employment, to signal ability to firms, or to improve their productivity, each decision in hopes of earning higher wages upon graduation. The choices workers make regarding schooling and skill acquisition are further complicated by two ubiquitous features across countries: imperfect screening of skills by firms, and ever increasing global integration of national economies. In this paper we provided a tractable framework to analyze a rich set of educational behaviors in the global economy.

A key feature of this analysis is to incorporate both signaling and productivity enhancing motives for education simultaneously. More than simply providing realism, allowing both incentives to weigh on worker behavior allows us to match several stylized facts regarding educational attainments and labor market outcomes. For instance, we have shown that imperfect screening of worker skills by firms reduces the incentives of workers to use education to acquire highly productive skills, but can increase the incentives of works to use education to signal ability. This potential for 'too many' college educated workers and still 'too few' high skill workers corresponds to common criticisms of the distortions among the labor force of developed countries. Also, across several countries rising wage inequality in recent decades has been concentrated within groups of college educated workers. Such variation in wages among workers with similar observed educational attainments is inconsistent with education being solely a mechanism for workers to signal abilities, or solely to enhance their productivity.

Worker skills are intimately linked with several aspects of the global economy, including the propensity of firms to export/import, the likelihood of being acquired by foreign multinationals, or even the potential to gain from international opportunities. We have shown that globalization can have a substantial impact on schooling and skill acquisition behavior among the domestic workforce. With imperfect screening of skills by firms, both the choices to go to school and to become high skilled are distorted. We have shown that while globalization can ease one of these distortions, it never alleviates both. Finally, our results demonstrate that the extent of firms engaged in international markets is a key fact in determining how workers respond to opening international markets. 


\section{$\underline{\text { Appendix }}$}

Result A.1: Our goal is to show that the $\mathrm{H}$ curve is flatter than the $\mathrm{L}$ curve. The slope of the $\mathrm{H}$ curve is $\frac{-H_{S}}{H_{E}}$ and the slope of the $L$ curve is $\frac{-L_{S}}{L_{E}}$. Thus, the $H$ curve is flatter if

$$
-\frac{H_{S}}{H_{E}}<-\frac{L_{S}}{L_{E}}
$$

After substitution and cross-multiplication, this is equivalent to

$$
D \equiv L_{S} H_{E}-H_{S} L_{E}=C_{S}^{\prime}\left(a_{S}\right) C_{E}^{\prime}\left(a_{E}\right)+C_{S}^{\prime}\left(a_{S}\right) \frac{\lambda w_{L}}{\phi} \phi_{E}-C_{E}^{\prime}\left(a_{E}\right) \frac{w_{L}}{\phi} \phi_{S}>0
$$

Which holds for all $a_{S}$ and $a_{E}$. Thus, the $\mathrm{H}$ curve is flatter than the $\mathrm{L}$ curve and $\mathrm{D}>0$.

Result A.2: We want to show that the Relative Supply curve is upward sloping. Substituting from (1), (5) and (6) into (12) we obtain

$$
\frac{X}{Y}=\frac{b\left[S_{L}+(1-\lambda) \theta S_{H}\right]+\lambda h S_{H}}{U+S-S_{L}-S_{H}-N_{b} F_{b}-N_{m} F_{m}}
$$

Now use (9) and (10) to substitute for $S_{L}$ and $S_{H}$ and then collect terms to obtain

$$
\frac{X}{Y}=\frac{S[b \theta(1-\lambda)+\lambda h]-b G\left(a_{S}\right)-[b(\theta-1)+\lambda(h-\theta b)] G\left(a_{E}\right)}{U+G\left(a_{S}\right)\left[1+b \frac{F_{b}}{\overline{\bar{x}}_{b}}\right]-S\left[b \theta(1-\lambda) \frac{F_{b}}{\overline{\bar{x}}_{b}}+\lambda h h_{\overline{\bar{x}_{m}}}\right]+G\left(a_{E}\right)\left[b(\theta(1-\lambda)-1) \frac{F_{b}}{\overline{\bar{x}}_{b}}+\lambda h \frac{F_{m}}{\overline{\bar{x}}_{m}}\right]}
$$

Since $\theta>1, h>\theta b$ and $\theta(1-\lambda)>1$, the rest of the proof follows directly from Lemma 2 . \#

Result A.3: We are interested in equilibria in which all basic firms hire workers from the low-skill pool and all modern firms hire workers from the high skill pool. Of course, it may be possible to have an equilibrium in which basic firms hire from both pools and modern firms hire from only the high-skill pool, but here we show that such a circumstance can only arise in equilibrium for a knife-edge set of parameters. Suppose that some firms that adopt the basic technology choose to hire high skill workers who pass the screening exam, just as modern firms. Workers that pass the screening exam would only accept jobs at basic firms if they paid same wage as modern firms. Then in this case, the free entry condition for basic firms that hire a high skill work force is given by

$$
F_{b}=\left(p-\frac{w_{H}}{\theta b}\right) \bar{x}_{b}
$$

and the free entry condition for modern firms remains equation (3). We can then use these two equations to solve for $w_{H}$ and $p$ in an equilibrium where basic firms also hire high skill workers. Specifically,

$$
w_{H}=\theta b h \frac{F_{m} / \bar{x}_{m}-F_{b} / \bar{x}_{b}}{h-\theta b} \quad \text { and } \quad p=\left(\frac{h F_{m} / \bar{x}_{m}-\theta b F_{b} / \bar{x}_{b}}{h-\theta b}\right) \text {. }
$$

Note that high skill wages and prices in an equilibrium where basic firms recruit high skill workers are function only of the parameters of the model. Put differently, such an equilibrium can only arise for a knife-edge set of parameters. 


\section{$\underline{\text { References }}$}

Acemoglu, Daron and Jorn-Steffen Pischke (1998). Why do firms train? Theory and evidence. Quarterly Journal of Economics, 113(1): 78-118.

Atkin, David (2012). Endogenous skill acquisition and export manufacturing in Mexico. Yale University Working Paper.

Becker, Gary (1964). Human Capital. Columbia University Press.

Berg, Ivar (1970). Education and Jobs: The Great Train Robbery. Praeger Publishers, New York, NY.

Bernard, Andrew and J. Bradford Jensen (1999). Exceptional exporter performance: Cause, effect or both? Journal of International Economics, 47(1): 1-25.

Bernard, Andrew, Jonathan Eaton, J. Bradford Jensen, and Samuel S. Kortum (2003) Plants and productivity in international trade. American Economic Review 93(4): 1268-1290.

Bernard, Andrew, J. Bradford Jensen, Stephen Redding and Peter K. Schott (2007). Firms in international trade. NBER working paper 13054.

Bernard, Andrew, J. Bradford Jensen, Stephen Redding and Peter K. Schott (2012) The empirics of firm heterogeneity and international trade. Annual Review of Economics, 4(1): 283-313.

Bernard, Andrew, J. Bradford Jensen, and Peter K. Schott (2006) Trade costs, firms and productivity. Journal of Monetary Economics, 53, pp. 917-937.

Bils, Mark and Peter J. Klenow (2000) Does schooling cause growth? American Economic Review 90(5): 1160-1183.

Blanchard, Emily and Gerald Willmann (2011). Trade, education and the shrinking middle class. Dartmouth College Working Paper.

Blankenau, William and Gabriele Camera (2006). A simple theory of skill accumulation and schooling decision. Review of Economic Dynamics, 9(1): 93-115.

Bougheas, Spiros, Richard Kneller and Raymond Riezman (2011). Optimal education policies and comparative advantage. Pacific Economic Review 16(5): 538-552.

Bougheas, Spiros and Raymond Riezman (2012). Market entry costs, underemployment and international trade. University of Nottingham Working Paper.

Card, David and Thomas Lemieux (1996). Wage Dispersion, Returns to Skill, and Black-White Wage Differentials. Journal of Econometrics 74(2): 319-361

Carneiro, Pedro; James J. Heckman and Edward J. Vytlacil (2011). Estimating marginal returns to education. American Economic Review, 101(6): 2754-81.

Ciccone, Antonio and Giovanni Peri (2011) Schooling supply and the structure of production: Evidence from US States 1950-1990. NBER Working Paper \# 17683 
Dobbs, Richard; Anu Madgavkar; Dominic Barton; Eric Labaye; James Manyika; Charles Roxburgh; Susan Lund and Siddarth Madhav (2012). The World at Work: Jobs, Pay, and Skills for 3.5 Billion People. McKinsey Global Institute, Washington DC.

Doms, Mark; Timothy Dunne and Kenneth Troske (1997). Workers, wages and technology. Quarterly Journal of Economics, 112(1): 253-90.

Egger, Hartmut and Udo Kreickemeier (2012). Fairness, trade, and inequality. Journal of International Economics, 86(2): 184-96.

Falvey, Rodney; David Greenaway and Joana Silva (2010). Trade liberalization and human capital adjustment. Journal of International Economics, 81(2): 230-39.

Fang, Hanming (2006). Disentangling the college wage premium: Estimating a model with endogenous education choices. International Economic Review, 47(4): 1151-85.

Fernandes, Ana (2007). Trade policy, trade volumes and plant-level productivity in Columbian manufacturing industries. Journal of International Economics, 71(1): 52-71.

Findlay, Ronald and Henryk Kierzkowski (1983). International trade and human capital: A simple general equilibrium model. Journal of Political Economy, 91(6): 957-78.

Freeman, Richard (1975). Overinvestment in college training? Journal of Human Resources, 10: 287311.

Freeman, Richard (1976). The Overeducated American. Academic Press; New York, NY.

Elhanan Helpman; Oleg Itskhoki; and Stephen Redding (2010). Inequality and unemployment in a global economy. Econometrica, 78(4): 1239-83.

Hickman, Daniel and William Olney (2011). Globalization and investment in human capital. Industrial and Labor Relations Review, 64(4): 654-72.

Krugman, Paul (2000). And now for something completely different: An alternative model of trade, education and inequality. In The Impact of International Trade on Wages (R. Feenstra, ed). National Bureau of Economic Research.

Lange, Fabian (2007). The speed of employer learning. Journal of Labor Economics, 25(1): 1-35

Lemieux, Thomas (2006a). Postsecondary education and increasing wage inequality. American Economic Review 96(2): 195-199

Lemieux, Thomas (2006b). Increasing residual wage inequality: Composition effects, noisy data, or rising demand for skill? American Economic Review 96(3): 461-98

Leuven, Edwin and Hessel Oosterbeek (2011). Overeducation and mismatch in the labor market. In Handbook of the Economics of Education, Vol. 4 (Hanushek, Machin and Woessmann, eds). Amsterdam: North Holland.

Lileeva, Alla and Daniel Trefler (2007). Improved access to foreign markets raises plant-level productivity...for some plants. Quarterly Journal of Economics 125(3): 1051-1099 
Matgouranis, Christopher (2010). The underemployed college graduate. Blog for The Center for College Affordability and Productivity, see http://centerforcollegeaffordability.org/archives/1761.

Mincer, Jacob (1974). Schooling, Experience and Earnings. Columbia University Press.

Murray, Charles (2009). Real Education: Four Simple Truths for Bringing America's Schools Back to Reality. Three Rivers Press (Random House); New York, NY.

Pavcnik, Nina (2003). What explains skill upgrading in less developed countries? Journal of Development Economics, 71: 311-28.

Ranjan, Priya (2001). Dynamic Evolution of Income Distribution and Credit-Constrained Human Capital Investment in Open Economies Journal of International Economics, 55(2).

Redding, Stephen and Peter Schott (2003). Distance, skill deepening and development: Will peripheral countries ever get rich? Journal of Development Economics, 72(2): 515-41.

Roberts, Mark and James Tybout (1997). The decision to export in Columbia: An empirical model of entry with sunk costs. American Economic Review, 87(4): 545-63.

Rose, Colin (1993). Equilibrium and adverse selection. Rand Journal 24(4): 559-569.

Solomon, Deborah (2008). Head of the class: Questions for Charles Murray. New York Times Magazine (Sept. 21, 2008).

Spence, A. Michael (1973). Job market signaling. Quarterly Journal of Economics, 87(3): 651-60.

Vedder, Richard (2010). Why did 17 million students go to college? The Chronicle of Higher Education, Blog on October 20, 2010, see http://chronicle.com/blogs/innovations/why-did-17-millionstudents-go-to-college/27634.

Vogel, Jonathan (2007). Institutions and moral hazard in open economies. Journal of International Economics, 71(2): 495-514.

Wilson, Charles (1980). The nature of equilibrium in markets with adverse selection. Bell Journal of Economics, 11: 108-30.

Wood, Adrian and Cristobal Ridao-Cano (1999) Skill, trade and international inequality. Oxford Economic papers 51: 89-119

2012 Talent Shortage Survey Research Results, ManpowerGroup, Milwaukee, WI, see www.manpowergroup.us/campaigns/talent-shortage2012/pdf/2012_Talent_Shortage_Survey_Results_US_FINALFINAL.pdf 


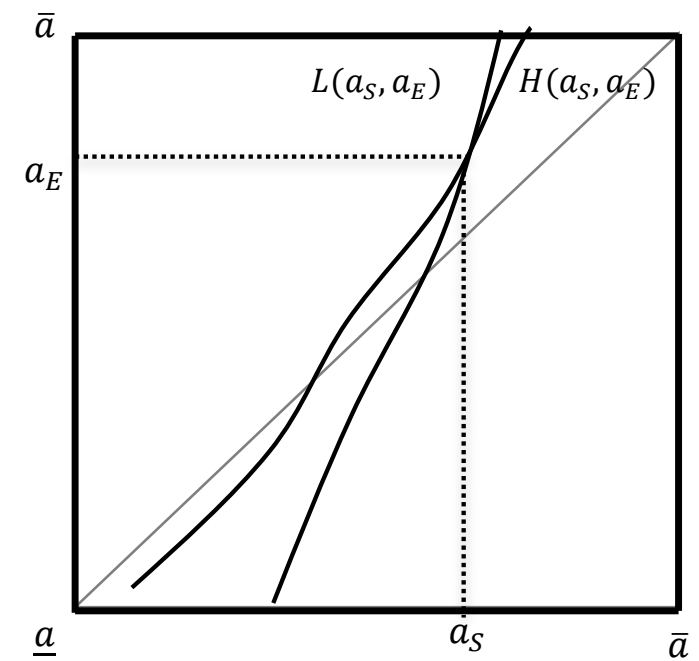

Figure 1: Equilibrium Education Behavior

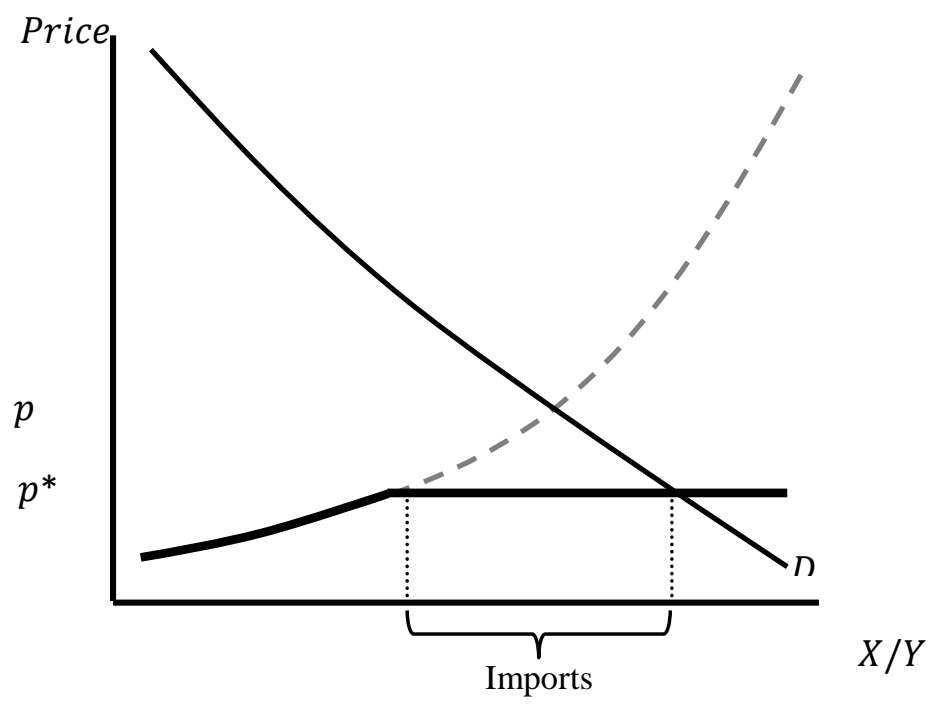

Figure 2: Equilibrium in a Small Importing Country 


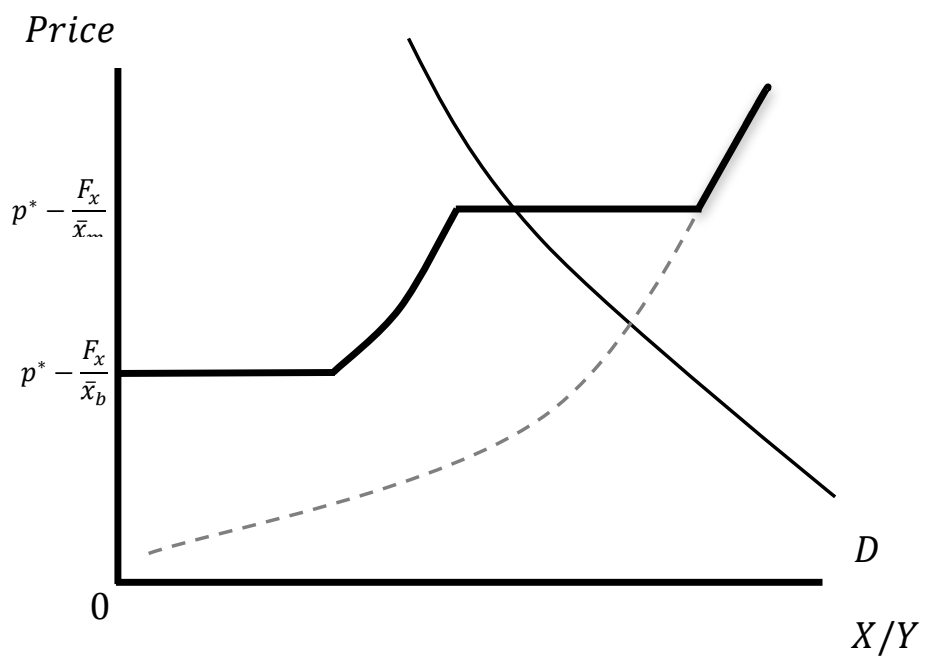

Figure 3: Equilibrium in a Small Exporting

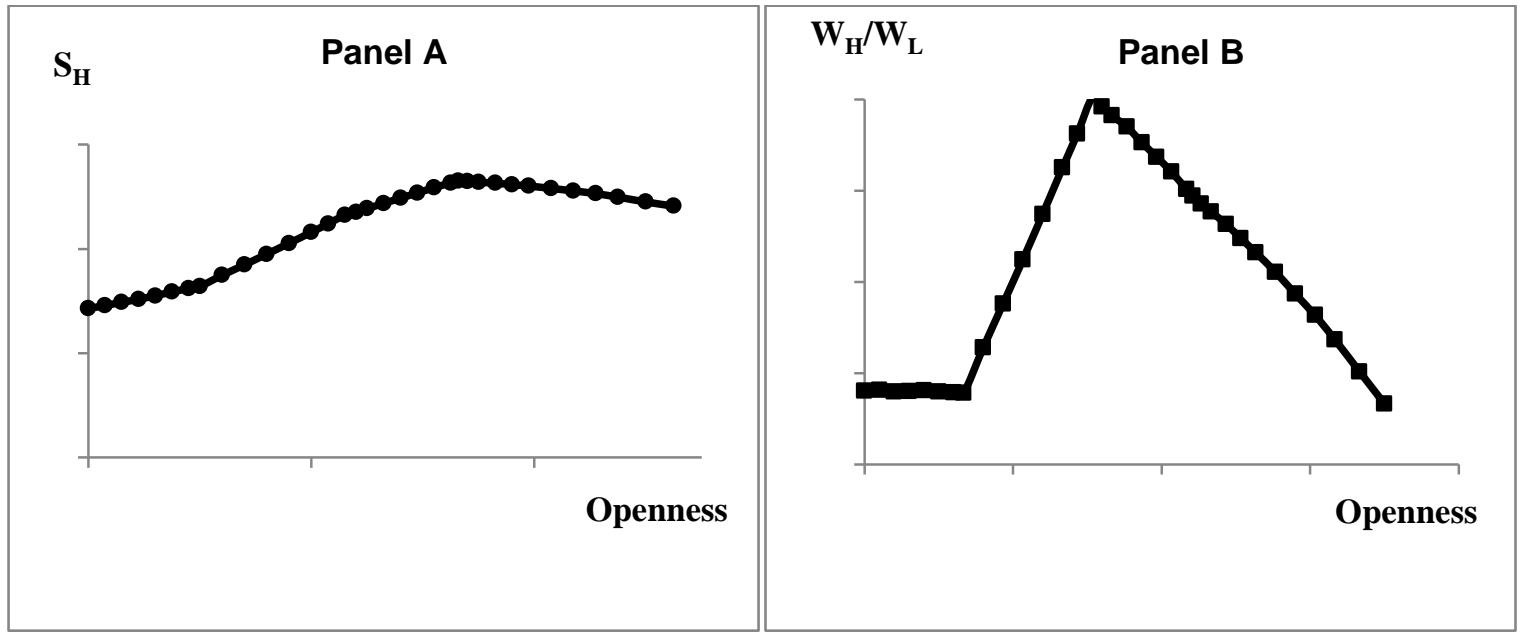

Figure 4: Numerical Results for the Effects of Trade with Monopolistic Competition 